NBER WORKING PAPER SERIES

\title{
PAYING A PREMIUM ON YOUR PREMIUM? CONSOLIDATION IN THE U.S. HEALTH INSURANCE INDUSTRY
}

\author{
Leemore Dafny \\ Mark Duggan \\ Subramaniam Ramanarayanan \\ Working Paper 15434 \\ http://www.nber.org/papers/w15434
}

\author{
NATIONAL BUREAU OF ECONOMIC RESEARCH \\ 1050 Massachusetts Avenue \\ Cambridge, MA 02138 \\ October 2009
}

We are grateful for helpful comments by Michael Chernew, Julie Cullen, Roger Feldman, Chris Snyder, Alan Sorensen, seminar participants at American University, Brown University, Dartmouth College, the Department of Justice, Harvard University, Ohio State University, UCLA, University of Rochester, University of Michigan, Wharton, and participants at the American Economic Association Annual Meetings, the International Industrial Organization Conference, the American Society of Health Economists Conference, the 20th Annual Health Economics Conference, the University of British Columbia Summer Industrial Organization Conference, the Searle Center Symposium on Antitrust Economics and Policy, the NBER Summer Institute, the "New Perspectives on Health and Health Care Policy" conference at the Federal Reserve Bank of Chicago and the HEC Montreal Conference on the Industrial Organization of Healthcare. We thank Michael Chernew, Jose Guardado, Woolton Lee, and Dennis Scanlon for valuable discussions on key data sources. Dafny gratefully acknowledges funding from The Searle Center on Law, Regulation, and Economic Growth at the Northwestern University School of Law. The views expressed herein are those of the author(s) and do not necessarily reflect the views of the National Bureau of Economic Research.

NBER working papers are circulated for discussion and comment purposes. They have not been peerreviewed or been subject to the review by the NBER Board of Directors that accompanies official NBER publications.

(C) 2009 by Leemore Dafny, Mark Duggan, and Subramaniam Ramanarayanan. All rights reserved. Short sections of text, not to exceed two paragraphs, may be quoted without explicit permission provided that full credit, including $\odot$ notice, is given to the source. 
Paying a Premium on Your Premium? Consolidation in the U.S. Health Insurance Industry Leemore Dafny, Mark Duggan, and Subramaniam Ramanarayanan

NBER Working Paper No. 15434

October 2009, Revised August 2010

JEL No. I11,L1,L4

\begin{abstract}
We examine whether and to what extent consolidation in the U.S. health insurance industry is leading to higher employer-sponsored insurance premiums. We make use of a proprietary, panel dataset of employer-sponsored healthplans enrolling over 10 million Americans annually between 1998 and 2006 to explore the relationship between premium growth and changes in market concentration. We exploit the differential impact of a large national merger of two insurance firms across local markets to estimate the causal effect of concentration on market-level premiums. We estimate real premiums increased by approximately 7 percentage points (in a typical market) due to the rise in concentration during our study period. We also find evidence that consolidation facilitates the exercise of monopsonistic power vis a vis physicians, whose absolute employment and relative earnings decline in its wake.

Leemore Dafny

Department of Management and Strategy

Kellogg School of Management

Northwestern University

2001 Sheridan Road

Evanston, IL 60208-2001

and NBER

1-dafny@kellogg.northwestern.edu

Mark Duggan

University of Maryland

Department of Economics

3115L Tydings Hall

College Park, MD 20742

and NBER

duggan@econ.bsos.umd.edu

Subramaniam Ramanarayanan

UCLA Anderson School of Management

110 Westwood Plaza, D-513

Los Angeles, CA 90095

subbu@anderson.ucla.edu
\end{abstract}


Although the majority of all healthcare expenditures in the U.S. are funneled through the private health insurance industry, few researchers have examined whether the industry itself is contributing to rising health insurance premiums. This possibility has become ever more salient as consolidations continue in this highly-concentrated sector. In 2001, the American Medical Association (AMA) reported nearly half of the 40 largest Metropolitan Statistical Areas (MSAs) were "highly concentrated," as defined by the Horizontal Merger Guidelines issued by the U.S. Department of Justice and the Federal Trade Commission (1992). By 2008, the AMA expanded its annual report to include 314 geographic areas (mainly MSAs), 94 percent of which were found to be highly concentrated. ${ }^{1}$ During this seven-year period, the average, inflation-adjusted premium for employer-sponsored family coverage rose 48 percent (to $\$ 12,680$ in 2008), ${ }^{2}$ while real median household income declined by 2 percent to $\$ 50,303$ (Census Bureau, 2009).

This study examines whether there is a causal link between changes in market concentration and the recent growth in health insurance premiums. From a theoretical standpoint, both the sign and the magnitude of the effect of concentration on insurance premiums are ambiguous. On the one hand, increases in market concentration may allow health insurers to raise their markups, leading to higher premiums. On the other hand, increases in market share may strengthen insurers' bargaining positions vis a vis healthcare providers, leading to reduced outlays and lower premiums. In addition, there are many potential sources of efficiency gains from consolidation, including economies of scale in IT investing and disease management programs, which would also reduce costs and optimal premiums. ${ }^{3}$ The net effect on insurance premiums is thus ultimately an empirical question.

The key challenges to empirically estimating such a link are adequate data and exogenous variation in market concentration. Comprehensive data on a large sample of healthplans are extremely difficult to obtain because contracts are customized for each buyer across many

\footnotetext{
1 "Competition in Health Insurance: A Comprehensive Study of U.S. Markets," American Medical Association, 2001 and 2008. These figures are based on the reported levels of the Herfindahl-Hirschman Index for HMOs and PPOs combined. Estimates are not strictly comparable over time due to changes in methodology and sample selection. For example, self-insured HMOs are generally included in 2001 but excluded in 2008. The Horizontal Merger Guidelines define markets with HHI > 1,800 as "highly concentrated."

${ }^{2}$ The corresponding increase for single coverage was 44 percent. Premiums include both employer and employee contributions, and are adjusted to 2008 dollars by the authors using the CPI-U. Nominal monthly figures are reported in Employer Health Benefits 2009 Annual Survey, Kaiser Family Foundation/Health Research and Educational Trust Survey, http://ehbs.kff.org/.

${ }^{3}$ Rent transfers from providers to insurers are not efficiency gains, although they may reduce premiums.
} 
different dimensions, renegotiated annually, and considered highly confidential. In addition, premiums vary based on the demographics, health risks, and expenditure history (or "experience") of the insured population. Thus, it is difficult to calculate a standardized premium to enable comparisons across employers and/or markets.

To address these issues, we utilize detailed longitudinal data for the healthplans offered by a sample of more than 800 employers in 139 distinct geographic markets in the U.S. Our data spans the nine years between 1998 and 2006 with more than 10 million Americans represented in the sample each year. Our analysis focuses on the effect of concentration on the growth rate in average health insurance premiums for the same employer in a specific geographic market over time. This alleviates concerns about time-invariant unobservable differences in the risk profiles of employee groups and the characteristics of plans they utilize. We also utilize data on timevarying measures such as employee demographics, the types of plans offered (HMO, POS, etc.), and the generosity of benefit design.

After documenting trends in the level and growth of concentration (as measured by the sum of squared market shares, or HHI) in 139 distinct geographic markets, we estimate OLS models of the relationship between premium growth and concentration levels. We do not find evidence that premiums are rising more quickly in markets that are becoming more concentrated. Although these estimates are useful for descriptive purposes, they are unlikely to provide causal estimates of the impact of market structure on premiums. Differences in HHI across markets or even changes in HHI within markets - are likely to be driven by many factors that are not exogenous to premium growth. These include differences (or changes) in consumer preferences, product offerings and pricing strategies, and the market conduct of hospitals, physicians, and other health care providers. For example, consider a market with a struggling local economy. In such a market, consumers may flock to low-priced carriers, bringing about an increase in local market concentration and a simultaneous reduction in average premium growth. This pattern does not imply consolidations in such a market would reduce premium growth, ceteris paribus.

To obtain a credible estimate of the causal impact of concentration on premium growth, we exploit sharp and heterogeneous increases in local market concentration generated by the 1999 merger of two industry giants, Aetna and Prudential Healthcare. Both were national firms, active in most local insurance markets, and thus the merger had widespread impact. However, 
the pre-merger market shares of the two firms varied significantly across local markets, resulting in very different shocks to post-merger concentration. For example, in our sample the premerger market shares of Aetna and Prudential in Jacksonville, Florida were 19 and 24 percent, respectively, versus just 11 and 1 percent, respectively, in Las Vegas, Nevada. Holding all else constant, this implies an increase in post-merger HHI of 892 points in Jacksonville, but only 21 in Las Vegas. Focusing on the years immediately surrounding this merger, we examine the relationship between premium growth and HHI changes using these predicted changes as instruments for actual changes, and controlling as well as possible for changes in the characteristics of healthplans (such as copayment levels).

The point estimates indicate that rising concentration in local health insurance markets accounts for a small share of premium growth in recent years. Specifically, our instrumental variables estimates imply that the mean increase in local market HHI during 1998-2006 raised premiums by roughly 7 percent from their 1998 baseline, all else equal. Given private health insurance expenditures of $\$ 490$ billion in 1998, if this result is generalizeable then the "premium on premiums" by 2007 is on the order of $\$ 34$ billion per year, or about $\$ 200$ per person ${ }^{4}$ with employer-sponsored health insurance. ${ }^{5}$

Although our focus is on the exercise of market power by insurers in the output market, consolidation may also have important effects on input prices. Using data on earnings and employment of healthcare personnel, we exploit the differential impact across geographic markets of the Aetna-Prudential merger to examine whether there is a causal link between concentration and these outcomes. Our analysis indicates that the growth in insurer bargaining power following this consolidation resulted in lower earnings and employment growth for physicians, and higher earnings and employment growth for nurses. This suggests that insurers used their increased bargaining power with health care providers to substitute nurses for physicians.

\footnotetext{
${ }^{4}$ This compares to an average annual premium of $\$ 4,479$ for workers with single coverage (Source: 2007 Employer Health Benefits Survey conducted by the Kaiser Family Foundation)

${ }^{5}$ Source: National Health Expenditure Data provided by the Center for Medicare and Medicaid Services; available online at http://www.cms.hhs.gov/NationalHealthExpendData/. The vast majority of this spending is by employersponsored plans; just 9 percent of the non-elderly privately insured have policies that are not employment-based (Census Bureau, 2009). Additionally, this figure understates the size of the private health insurance industry as it excludes expenditures by Medicaid and Medicare managed care plans.
} 
The paper is organized as follows. Section I discusses prior related research. Section II describes the data in detail. We examine the association between local market concentration and premium growth in Section III. In Section IV we investigate whether a causal relationship exists between these two variables using the variation across geographic markets in the merger-induced increase in insurer concentration. Section V extends the analysis in Section IV, examining the impact of the merger-induced changes in concentration on other outcomes of interest such as the percent of enrollees in HMOs. Section VI describes our analyses of the relationship between changes in concentration and healthcare employment and earnings. Section VII concludes.

\section{Related Research}

Our study builds on research from two distinct streams of literature: studies of the relationship between market concentration and competitive outcomes in the empirical industrial organization literature, and studies of the health insurance industry, mainly from the health services literature. In this section, we summarize the key insights of each, and identify our contributions at the end.

\section{A. Price-Concentration Studies in Industrial Organization}

The structure-conduct-performance paradigm in industrial organization triggered a wave of empirical studies of the relationship between market concentration and profitability. ${ }^{6}$ Using cross-sectional data for a large number of industries, many of these studies documented a positive relationship between profits and concentration. ${ }^{7}$ This approach was famously critiqued by Harold Demsetz (1973), who argued that the observed relationship could also be explained by differences in efficiency across firms. ${ }^{8}$ Subsequent studies focus on price, an outcome less subject to this "efficiency critique."

\footnotetext{
${ }^{6}$ Although our discussion focuses on studies of horizontal consolidation, researchers have also investigated the impact of vertical consolidation on price (as well as other outcomes). Recent examples of such studies include Cuellar and Gertler (2005) on physician-hospital integration and Hortacsu and Syverson (2007) on integration in the cement and ready-mixed concrete industries.

${ }^{7}$ See Weiss (1989) for a summary of these early studies.

${ }^{8}$ This approach was also criticized on other fronts, particularly the failure to control for differences in economic factors across industries, and on the use of accounting measures of profitability.
} 
Recent studies in this literature rely on within-industry variation in concentration and price, primarily by using observations on different geographic markets. Most document higher prices in more concentrated markets. Examples include Morrison and Winston (1990) and Borenstein and Rose (1994) in airlines, Hannan (1992) in banking, and (Cotterill 1986) in grocery retailing. However, much of this work assumes market structure is exogenously determined with respect to price. Given many of the same unobservable factors determine both, regressions of price on concentration and observable controls likely yield biased estimates.

Recent studies have pursued two distinct approaches to surmount this endogeneity issue. One solution relies on a two-step estimation procedure. In the first step, the authors estimate an equilibrium model predicting the number of competing firms in a market. This model is then used to generate a correction term to include in the second-stage regression of price on concentration, much in the same way selection correction terms are included in wage regressions (Heckman 1979). Some recent examples include Manuszak and Moul (2008), who use this method to evaluate the prospective impact of the Staples-Office Depot merger, and Singh and Zhu (2006), who study auto rental markets. Mazzeo (2002) extends this approach to account for the impact of product differentiation by specifically allowing for differences in the competitive effects of firms with different product characteristics. This approach lends itself to estimating welfare changes and performing counterfactual experiments (such as estimating the effects of a merger), but it requires strong assumptions about the behavior of firms to enable an accurate characterization of market structure in the first-stage equation.

The second solution requires variables that can serve as instruments for market structure, i.e. measures that are correlated with market structure but uncorrelated with unobservable factors affecting price. Two of the best-known studies in this vein use lagged market structure as an instrument for current market structure: Evans, Froeb and Werden (1993) (airlines) and Davis (2004) (movie theaters). For example, Davis explores the relationship between within-theater variation in pricing and geographic market structure, using lagged counts of movie screens owned by own and rival chains within various distances as instruments for their current levels. He finds ownership structure has a statistically significant but economically small effect on admission prices charged to consumers. One limitation of this approach is that lags of an endogenous variable are only valid instruments under relatively strong assumptions. 
We also pursue an instrumental variables approach to estimate the causal relationship between market structure and price. Our instrument consists of market-specific shocks induced by a large national merger. To the extent these shocks are both correlated with observed changes in market structure and orthogonal to other determinants of premium growth, our estimates will be unbiased. We are unaware of other studies that explicitly use mergers to instrument for changes in market concentration, although there is certainly a related literature on merger effects. Although this literature is too vast to be summarized here, we note that most of the reduced-form estimates of merger effects suffer from selection bias. Markets or industries in which mergers occur are unlikely to be randomly selected, or to be more precise, to be selected in a way that is unrelated to other determinants of the outcomes of interest. Some merger analyses contend with this selection problem by exploiting a temporal shock that induces additional mergers, such as Kim and Singhal (1993) on airlines and Berry and Waldfogel (2001) on radio stations, or by using an instrument to predict which institutions merge (Dafny (2009) on hospital mergers). Hastings and Gilbert (2005) use an acquisition of a West Coast refinery as a source of exogenous variation in the degree of vertical integration across retail gasoline markets in 13 West Coast metropolitan areas and test for increases in rival firms' costs. A notable strength of this analysis is the inclusion of time-varying controls for the characteristics of gasoline stations, so the authors can measure the effect of integration on price, all else equal. If mergers affect the quality of products that are offered, it will be important to control for changes in quality when reporting the impact on price.

In this study, we exploit a single merger with different impacts across geographic markets. We carefully consider whether the merger we examine generates plausibly exogenous variation in market concentration. We address the possibility of contemporaneous quality changes by controlling for changes in observable measures of quality (such as copayment levels and plan type), and by using these measures as outcome variables in supplementary analyses. ${ }^{9}$

\section{B. Studies Focusing on the Health Insurance Industry}

Several studies published in health economics or health services journals examine the relationship between industry structure and insurance price (i.e., premiums). Robinson (2004) uses a database of state regulatory filings to study the state-level market structure of commercial

\footnotetext{
${ }^{9}$ Unfortunately, we do not observe all measures of plan quality, including for example the breadth of the physician or hospital network.
} 
insurance carriers in 2003. He finds the largest firm controls at least a third of the market in almost 40 states in 2002-03. The top 3 insurance firms control over 50 percent of total enrollment in almost all states. Using a variety of other sources, Robinson also documents a sharp increase in insurer revenues and profits over the time period 2000-2003. There is, however, no attempt to establish a causal relationship between these two phenomena.

Wholey, Feldman and Christianson (1995) examine the effects of HMO market structure (measured by the number of HMOs) on HMO premiums from 1988 to 1991. Their analysis uses the HMO (which may be national, regional, or local) as the unit of observation. Premiums are estimated as average premium revenue per member, and the market structure facing each HMO is a weighted average of the number of competitors in the geographic markets in which the HMO is active. The results suggest premiums decrease when entry occurs. However, the specifications do not include HMO fixed effects, so the results are subject to the usual biases arising from cross-sectional sources of identification. ${ }^{10}$

Our research complements recent work by Dafny (2010). Using the same dataset employed here, Dafny finds health insurers engage in "direct" price discrimination, charging higher premiums to firms with deeper pockets, as measured by operating profits. This evidence of price discrimination implies insurers possess and exercise market power in some local markets. Here, we focus on whether insurers use their market power to raise premiums overall, and by how much.

\section{Data}

Our primary source is the Large Employer Health Insurance Dataset (LEHID). LEHID contains information on all of the healthplans offered by a large sample of employers between 1998 and 2006, inclusive. It is gathered and maintained by a leading benefits consulting firm, and the employers included in the dataset have some past or present affiliation with the firm; Dafny (2010) presents evidence suggesting that the data are representative of insurance plans offered by large employers nationwide. LEHID captures more than 10 million non-elderly Americans every year, and affords us a number of advantages over other studies of the insurance

\footnotetext{
${ }^{10}$ In a related study, Feldman and Wholey (1996) use data on HMOs to estimate the effect of HMO mergers on premiums, and find that mergers do not affect HMO premiums except in the most competitive markets.
} 
industry. It includes the actual premium charged to every sampled employer for each health plan they offer. Several details are available for each health plan as well, including the identity of the insurance carrier, the plan type, and a summary measure of enrollee demographics. The microlevel data enables us to avoid the noise and error associated with high-level aggregation. We also make use of geographic market definitions supplied by the industry, as opposed to arbitrary geographic units that may correspond poorly to actual markets. Finally, the panel nature of the dataset permits us to eliminate cross-sectional differences across markets and employers as a source of identification for the relationship of interest.

Descriptive statistics for each year of data are presented in Table 1. The unit of observation is the healthplan-year. A healthplan is defined as a unique combination of employer, market, insurance type, insurance carrier, and plantype (e.g. Company X's Chicago-area fullyinsured Aetna HMO). We now discuss each of the components that jointly identify this unit of observation in turn.

The full dataset includes observations from 813 employers. Employers may enter or exit the sample at any time. The median number of years an employer is present in the sample is two. One-quarter of employers appear in the sample for 4 or more years. A non-trivial number of employers reappear after exiting. Most employers are large, multi-site, publicly-traded firms, such as those included on the Fortune 1000 list. The leading industries represented include manufacturing (110 employers), finance (101), and consumer products (73), although nonprofit and government sectors are also represented (43 in the "government/education" category).

Geographic markets are defined by the data source using 3-digit zipcodes. According to the data provider, the 139 markets reflect the geographic boundaries typically used by insurance carriers when quoting prices. Large metropolitan areas are separate markets, and nonmetropolitan areas are lumped together within state boundaries, (e.g., "New Mexico Albuquerque" and "New Mexico - except Albuquerque") ${ }^{11}$

The sample includes both fully-insured and self-insured plans. As these terms suggest, the former is "classical" insurance in which the insured pays the carrier to bear the risk of

\footnotetext{
${ }^{11}$ There is only one market that crosses state boundaries, "Massachusetts - Southern and Rhode Island." A few rural areas of the U.S. are explicitly excluded. A map of the markets is available in Dafny (2010).
} 
realized healthcare outlays. Many large employers choose to self-insure, outsourcing benefits management and/or claims administration but paying realized costs of care. Such employers can spread risk across large pools of enrollees, and may purchase stop-loss insurance to limit their remaining exposure. Per ERISA (the Employee Retirement Act of 1974), these plans are also exempt from state regulations (such as specific benefit mandates) and state insurance premium taxes. Even though insurance carriers do not bear the risks associated with medical expenditures under self-insurance, their role in administering claims and especially in negotiating provider discounts affords them the scope to potentially impose markups via steeper charges. (Selfinsured contracts typically include some combination of fees per employer, per employee, and/or per claim.)

In our sample, the fraction of plans that are fully insured declines from 45 to 20 percent between 1998 and 2006. The decline is somewhat less precipitous when calculated using the fraction of enrollees - 42 to 25 percent - but clearly remains an important phenomenon in the data. $^{12}$ The decline is not unique to our data source: it has been corroborated in the Kaiser Family Foundation/Health Retirement Education Trust Annual Survey of Employer Benefits and the Medical Expenditure Panel Survey-Insurance Component (MEPS-IC), and appears to be especially pronounced among the very largest firms. ${ }^{13}$ We revisit this issue again when discussing our unit of analysis below - the "employer-market-year" cell.

Each firm that administers any plan in the data is labeled an "insurance carrier."14 During the entire study period, there are 357 carriers that serve at least one employer, and 195 that serve 5 or more. The smaller carriers tend to be local or regional firms, or sometimes "third party administrators" who pay claims and contract with another firm to "rent" its network of providers and associated discounts. The industry is highly concentrated and becoming more so over time. Figure 1 presents the four-firm concentration ratio for the nation as a whole, estimated using the LEHID sample. This measure increased from an impressive 58 percent in

\footnotetext{
${ }^{12}$ The reasons for this decline are the subject of a current research project.

${ }^{13}$ We are grateful to Kosali Simon for tabulating the MEPS-IC data to investigate this trend.

${ }^{14}$ Blue Cross and Blue Shield (BC/BS) affiliates are all assigned the same carrier ID. (Note: both Wellpoint and Anthem (before it was acquired by Wellpoint) own BC/BS affiliates, so they also have the BC/BS carrier ID. Given we calculate concentration within each market, and there are only a handful of markets in which $\mathrm{BC} / \mathrm{BS}$ affiliates complete, the uniform coding of these affiliates is unlikely to be consequential for our analysis.
} 
1998 to 79 percent in 2006. ${ }^{15}$ As we illustrate in the following section, concentration ratios within local markets - arguably where most of the competition takes place - are much higher. ${ }^{16}$

The plan types, ordered from most to least restrictive in terms of provider choice, are Health Maintenance Organization (HMO), Point of Service (POS), Preferred Provider Organization (PPO), and Indemnity. HMOs and POS plans control utilization of care through primary-care physicians ("gatekeepers"). Only in-network providers are covered by HMOs, while POS plans provide some coverage for out-of-network providers (once the gatekeeper has approved the service in question). PPOs engage in less utilization management, and like POS plans, typically cover out-of-network care at a reduced rate. Finally, indemnity plans are traditional fee-for-service arrangements in which benefits do not depend on the network status of the provider. As Table 1 reveals, the composition of plan types fluctuated during the study period, with a clear resurgence of PPOs toward the end of the study period.

In addition to the elements that jointly define a plan, our data set includes the following variables: premium, demographic factor, plan design factor, and number of enrollees. Premium is expressed as an average amount per enrollee (i.e. a covered employee); it therefore increases with the average family size of enrollees in a given plan. Premium combines employer and employee contributions, and for self-insured plans it is a projection of expected costs per enrollee (including estimated administrative fees paid to an insurance carrier). These projections may include a partial risk premium if the employer purchases stop-loss coverage; whether stop-loss coverage is purchased is not captured in the data. Because the forecasts are used for budgeting and to establish employee premium contributions, they are carefully developed and vetted. Employers often hire outside actuaries and benefits experts (such as our source) to assist in formulating accurate projections.

Demographic factor is a measure that reflects family size, age, and gender composition of enrollees in a given plan. All of these are important determinants of average expected costs per enrollee in a plan. Plan design factor captures the generosity of benefits within a particular

\footnotetext{
${ }^{15}$ This calculation identifies all Blue Cross/Blue Shield plans as the same carrier, although there are roughly forty independent companies that operate these plans. However, with rare exceptions the plans do not serve overlapping territories and hence cooperate with one other.

${ }^{16}$ The notable exception is the market for multisite employers interested in a uniform plan across all sites. Our data do not include an identifier for jointly-negotiated plans.
} 
carrier-plan type, with an emphasis on the degree of coinsurance and copays. Both factors are calculated by the source, and the formulae were not disclosed. Higher values for either will result in higher premiums. For example, a plan will have a high demographic factor if employees enrolled in that plan tend to have a large number of dependents. Similarly, a plan that has very low copayments for office visits will have a higher value for plan design.

The LEHID also includes the number of enrollees in each plan, excluding dependents, who are accounted for by the demographic factor variable described above. The total number of enrollees in all LEHID plans averages 4.7 million per year. Given an average family size of more than 2, this implies over 10 million Americans are part of the sample in a typical year, representing approximately 7 percent of those with employer-sponsored insurance (ESI) during this period, and a much larger share of those insured through large firms.

We supplement the LEHID data with time-varying measures of local economic conditions (the unemployment rate, as reported by the Bureau of Labor Statistics), a measure of healthcare utilization (Medicare costs per capita, as reported by the Center for Medicare and Medicaid services), and the concentration of the hospital industry (HHI as calculated by the authors using the Annual Surveys of Hospitals administered by the American Hospital Association). ${ }^{17}$ As the first two measures are reported at the county-year level, and LEHID markets are defined by 3-digit zipcodes, we make use of a mapping between zipcodes and counties and where necessary, use population data to calculate weighted average values for each geographic market and year.

As noted above, we perform most analyses using data aggregated to the employermarket-year level. Table 2 presents descriptive statistics for this unit of observation. Because our primary outcome is growth in health insurance premiums (in order to avoid cross-sectional identification of the coefficients of interest), aggregating the data to the employer-market-year level enables us to use a much larger proportion of the data. With the healthplan-level data, growth in premium is undefined when an employer terminates a particular plan. Analogously, new plans can only enter the analysis after multiple observations are available. Changes to plan

\footnotetext{
${ }^{17}$ To calculate HHI for each geographic market and year, we use data on the number of beds for all general hospitals located in the set of 3-digit zipcodes that define the market, assigning hospitals with the same "system ID" to a common owner.
} 
offerings are quite common in our data (24 percent of plans in year t whose firm-markets are still present in year $\mathrm{t}+1$ no longer exist). Moreover, changes in market concentration may affect the insurance carriers and plan types chosen by employers, so we do not want a priori to eliminate this substitution from our sample. ${ }^{18}$ Given this aggregation, both fully and self-insured plans must be included together in the analysis to ensure the set of employees represented over time is the same (but for hiring, attrition, and changes in the decision to sign up for ESI).

Before proceeding to the analyses, we offer some remarks regarding the representativeness of the LEHID data. As previously stated, LEHID consists primarily of large, multisite employers. ${ }^{19}$ In Appendix Figure 1, we compare annual premium growth observed in LEHID with annual premium growth for all firms, as reported by the Kaiser Family Foundation (KFF) and the Health Research and Educational Trust (HRET). ${ }^{20}$ The KFF/HRET Annual Survey of Employer-Sponsored Health Benefits is specifically designed to yield nationallyrepresentative data. Although we would not expect premium levels to be similar across the two samples, if growth rates are similar this would suggest the results of our study are applicable to a broader sample of employers because all specifications rely on premium growth over time. The graph reveals that the trends in both samples are very similar over time.

One possible concern with the LEHID data is that the probability of being included in the sample may vary substantially across areas. However, Dafny (2010) reports that the ratio of sampled enrollees to total insured lives (available at the county-level from the US Census of 2000) varies little across geographic markets. ${ }^{21}$ This provides further evidence that the sample accurately captures the typical healthplans offered by large employers in the U.S.

\footnotetext{
${ }^{18}$ As an example of the frequency with which this occurs, consider employer-market pairs that are present in both 1999 (the year of the Aetna-Prudential merger) and 2002. More than half of the plans offered by these firms in 1999 are no longer present in 2002, either because the employer switched to different carriers or because it changed the type of plan with the same carrier.

${ }_{19}$ More than 96 percent of enrollees represented in LEHID are employed by firms that have more than 5000 employees. This compares to a national figure of 37 percent across all firms (KFF, 2010).

20 The KFF/HRET survey randomly selects public and private employers to obtain nationally-representative statistics for employer-sponsored health insurance; approximately 2000 employers respond each year. The micro data are not publicly available, nor is the sample designed to provide estimates at the market level.

${ }^{21}$ In the appendix, we describe our efforts to compare the LEHID-based estimates of market structure with those obtained by other researchers using the proprietary InterStudy database, specifically Scanlon, Chernew, and Lee (2006). Scanlon et al (2008) use these data to show that increased levels of HMO competition are not associated with increases in plan quality. InterStudy reports some enrollment and premium figures at the insurer and MSA level, but for reasons outlined in the Appendix, it is not an ideal source for our purposes.
} 


\section{Is Premium Growth Correlated with Local Market Concentration?}

In this section, we examine the relationship between the growth in health insurance premiums and local market concentration. We begin by describing the distribution of marketlevel HHI and how this has changed over time. Next, we estimate OLS regressions relating premium growth at the employer-market level to the corresponding market HHI. We include market fixed effects in our models, so that we identify the coefficient of interest using changes in within-market HHI. The richness of the data also permits us to control for important timevarying differences (such as the percent of enrollees in HMOs and the degree of copays). Although interesting as a descriptive exercise, this analysis is unlikely to yield credible estimates of the impact of changes in market structure on premium growth, as changes in market structure are unlikely to be exogenous. In Section IV, we estimate this causal relationship by using the Aetna-Prudential merger to construct an instrument for market concentration.

\section{A. Market Structure of Large Group Insurance Markets, 1998-2006}

During our 9-year study period, the average market-level HHI (estimated using our sample, on a scale from 0 to 10,000) increased from 2,286 to $2,984 .{ }^{22}$ Using the categorization from the Horizontal Merger Guidelines, the fraction of markets falling into the top "highly concentrated" category $(\mathrm{HHI}>1,800)$ rose from 68 to 99 percent. Thus, our data are consistent with the conclusions of the well-publicized reports issued by the American Medical Association: local health insurance markets are highly concentrated and becoming more so over time.

Figure 2 presents histograms of the market-level changes in HHI, separately for 1998-2002, 2002-2006, and 1998-2006. The biggest increases occurred during the second half of the study period, but sizeable increases are present in the first half as well. Between 1998 and 2002, 53 percent of markets experienced increases in HHI of 100 points or more, and 25 percent saw increases of 500+ points. The corresponding figures for 2002 to 2006 are 78 and 53 percent, respectively. The Merger Guidelines provide a helpful frame of reference for interpreting these changes. According to the Guidelines, mergers resulting in an increase of $100+$ points are

\footnotetext{
${ }^{22}$ To gauge the impact of this change on concentration, consider the following two examples. A market with five insurers, four of which each have a 24 percent market share, would have an HHI of 2,281. A market with four insurers, three of which each have a market share of 31.33 percent, would have an HHI of 2,981.
} 
"presumed...likely to create or enhance market power or facilitate its exercise." 23 There is wide variation in the magnitude of changes in HHI across markets, notwithstanding the fact that most are positive.

The reasons for these changes in HHI (apart from sample composition, which we discuss below), can be subdivided into "structural" (related to entry, exit, and consolidation of insurance carriers) and "non-structural" sources. Using data on fully-insured HMOs only, Scanlon et al (2006) report that 61 to 65 percent of the variation in HHI between 1998 and 2002 is attributable to changes in market structure. Structural changes (primarily due to consolidation or exit) are also important in our sample: the mean number of carriers per market declined from 18.9 in 1998 to 9.6 in $2006 .{ }^{24}$ Figure 3 contains histograms for changes in the number of carriers. As the figure shows, between 1998 and 2002, the modal net loss is 1 to 3 carriers; the corresponding range for 2002 to 2006 is 4 to 6 carriers. Of course, neither structural nor non-structural sources of changes in HHI can be presumed exogenous to other determinants of premium growth. Exit and consolidation of carriers may be impacted by expectations of premium growth, and consumer preferences simultaneously determine market shares and premium growth.

\section{B. OLS Estimates of the Relationship between Market Structure and Premiums}

To explore the relationship between premium growth and market concentration, we begin by estimating equations of the following form:

$$
\begin{aligned}
\Delta \ln (\text { premium })_{\text {emt }} & =\alpha+\beta H H I_{m, t-1}+\mathrm{X}_{\mathrm{mt}-1} \vartheta+\Delta C_{\text {emt }}+\tau_{t}+\lambda_{m} \\
& {\left[+\varsigma_{e}\right]\left[+\omega \Delta \text { plan type shares } \text { emt }+\vartheta \Delta \text { plan design } n_{\text {emt }}\right]+\varepsilon_{\text {emt }} . }
\end{aligned}
$$

Stated in words, we model premium growth between year $t$ and year $t-1$ for a given employer $e$ in market $m$ as a function of lagged market characteristics (including $\mathrm{HHI}^{25}$ ), contemporaneous changes in observable characteristics of the insured population (such as demographics), and year

\footnotetext{
${ }^{23}$ Horizontal Merger Guidelines, Federal Trade Commission and Department of Justice, issued in 1992 and revised in 1997. Accessed at http://www.usdoj.gov/atr/public/guidelines/hmg.htm.

${ }^{24}$ As the data on HHI suggests, many of these carriers are quite small. This is due to the presence of many small self-insured plan administrators, particularly in the earlier part of the study period. Some of these administrators may not be active participants in a given market, i.e. they "rent networks" from other carriers so as to offer a particular client a consistent plan across all geographies.

${ }^{25}$ From a theoretical standpoint, the use of HHI for evaluating competitive effects is valid only under a Cournot model of competition, which might not accurately describe the health insurance market. We note this shortcoming but persist in using this measure because a majority of studies in the related literature use the HHI as a measure of concentration, as do the Horizontal Merger Guidelines.
} 
and market fixed effects. Market characteristics are lagged by one year because premiums are set prospectively, i.e. premiums for 2006 are determined in 2005. In addition to HHI, the market-year covariates (denoted by $\mathrm{X}_{\mathrm{mt}-1}$ ) include the unemployment rate (to capture local economic conditions), the log of per-capita Medicare costs (to capture trends in healthcare utilization), and the general, acute-care hospital Herfindahl index (to capture concentration in the provider market, which could independently lead to premium increases). Note these characteristics are included in level form (rather than first differences) to allow for a delayed response to changes in market structure or in local economic conditions.

In contrast, we anticipate concurrent premium responses to changes in characteristics measured at the employer-market-year level $\left(\Delta C_{e m t}\right)$, specifically demographic factor (which is dominated by changes in the average number of dependents who sign up for coverage) and the percentage of enrollees in self-insured plans. The year fixed effects capture national changes in premium growth, and the market fixed effects capture differences in average growth across markets. The inclusion of these fixed effects eliminates common national time-series and crosssectional differences in concentration as sources of identifying variation for $\beta$.

Results are presented in columns 1 through 3 of Table 3. In all models we discuss, HHI is measured on a scale from 0 to 1 , and standard errors are clustered by market. The first column corresponds to the baseline specification, which excludes the bracketed terms in equation (1). Column 2 adds employer fixed effects, which will affect the coefficient on HHI if employers with particularly high or low average premium growth are systematically located in markets with particularly high or low growth in HHI. Column 3 introduces controls for changes in the generosity of plans, namely the change in the percent of enrollees in each plan type (excluding POS, the omitted category), and the change in plan design. Relaxing constraints on provider choice and utilization (i.e. moving toward PPOs) should be associated with higher premiums. Increases in plan design should also result in higher premiums. Because substitution across plan types and modifications to plan design may constitute a response to changes in HHI, controlling for these terms is akin to using a Laspeyres price index as a dependent variable, i.e. using the change in price for a fixed product type and design. 
The OLS estimates reveal no significant association between concentration levels and premium growth, and the estimates change little upon inclusion of additional controls. ${ }^{26}$ However, we can only make causal inferences using this model if within-market variation in insurer concentration is uncorrelated with other unobserved determinants of premiums, and if variation in premium growth does not induce variation in concentration. There are good reasons to doubt the validity of these assumptions. For example, exits of carriers (and hence increases in HHI) may be more likely in markets where premium growth is expected to be low. Nonstructural changes in HHI may also generate a downward bias in the HHI coefficient. For example, if employers in markets with dim economic prospects substitute toward a low-priced "Walmart-style" carrier, HHI will increase while premiums decrease. Indeed, most plausible sources of endogeneity suggest the OLS coefficient will be downward-biased. Hence in the section that follows we pursue an instrumental variables approach.

\section{Do Increases in Local Market Concentration Cause Increases in Premiums?}

In this section, we estimate the causal effect of changes in market concentration on premium growth by exploiting shocks to local market concentration produced by mergers and acquisitions (M\&A). Because M\&A activity in local or regional markets may itself be motivated by expected trends in premium growth, we considered only large, non-local mergers as candidates for this analysis. We also ruled out mergers with insufficient pre or post periods (e.g. Aetna and NYLCare in 1998, the first year for which we have plan data), few overlapping markets, or very small shares in our sample for one of the merging parties (e.g. United Healthcare and MAMSI).

Only one merger remained: the Aetna-Prudential merger of 1999. Post-merger, the new firm (known as "Aetna") was widely reported to be the national's largest insurer, covering 21 million individuals. ${ }^{27}$ Importantly, and as we describe in detail below, there was substantial overlap in the local market participation of Aetna and Prudential prior to the merger, generating the potential for sizeable post-merger changes in local market concentration.

\footnotetext{
${ }^{26}$ For the most part, the coefficient estimates on the market-level control variables are statistically insignificant. The coefficient estimates on the employer-market controls are highly significant, and all have the expected signs. For example, a shift from $100 \%$ enrollment in POS plans (the omitted category) to $100 \%$ enrollment in HMO plans is associated with a 5 percent decline in premiums.

${ }^{27}$ Sanders, Alain L., "Will the Aetna-Prudential Merger Hurt the Patient?" TIME magazine, June 22, 1999.
} 
Our analysis is subdivided into four sections. First, we discuss the context for the merger, paying special attention to whether the timing was affected by anticipated, marketspecific changes in premium growth trends. Second, we estimate the impact of the merger on market concentration (the "first stage" analysis). In so doing, we document the range of premerger market shares for Aetna and Prudential, as well as the degree of pre-merger overlap. Third, we perform a reduced-form analysis, in which we examine the impact of the merger on premium growth. Fourth, we combine these analyses to produce our estimate of the causal impact of concentration on premiums.

\section{A. The Aetna-Prudential Merger of 1999}

In December 1998 Aetna Inc. announced its intention to purchase Prudential Health Care (hereafter Prudential) for $\$ 1$ billion. Prudential had been publicly searching for an acquirer since at least October of the year prior; it was widely reported to be losing money and its parent firm, Prudential Insurance Company of America, had decided to exit the health insurance business. Importantly, Aetna was an unlikely suitor, as it had recently closed another $\$ 1$ billion acquisition (of NYLCare), and had publicly stated that future acquisitions would not occur "for at least a year."28 In announcing the deal, Aetna's CEO claimed Prudential had 'made an offer we can't refuse. ${ }^{29}$ The deal closed in July 1999, after Aetna signed a consent decree to address concerns raised by the Department of Justice (DOJ). The DOJ alleged that after the merger, Aetna would have a market share for fully-insured HMOs of 63 percent (in Houston), and 42 percent (in Dallas). As a precondition to approve the merger, it required the divestment of all Houston and Dallas-area plans Aetna had acquired in the 1998 NYLCare purchase. (Ultimately, Aetna divested all NYLCare plans in Texas, affecting the entire state. ${ }^{30}$ )

According to industry analysts, Aetna's acquisition of Prudential was part of a strategic bet on the long-term viability of managed care. Originally focused on providing fee-for-service

\footnotetext{
${ }^{28}$ Freudenheim, Milt, “Aetna to Buy Prudential's Health Care Business for \$1 Billion,” The New York Times, December 11, 1998, Section C, page 1.

${ }^{29}$ Ibid

29 "Blue Cross and Blue Shield of Texas to Purchase NYLCare Texas Operations," Aetna press release, 9/14/1999, http://www.aetna.com/news/1999/pr_19990914.htm.
} 
plans to large, self-insured employers, Aetna gambled on the rising popularity of HMOs with the 1996 purchase of U.S. Healthcare, which offered fully-insured HMOs to small groups. The acquisitions of NYLCare (New York Life's healthcare unit) and Prudential soon followed; managed plans were also the dominant segment for these units. At its peak after the Prudential acquisition in 1999, the firm covered 21 million lives. However, enrollment fell rapidly thereafter, plateauing at 13 million in 2002. A 2004 article in Health Affairs declared Aetna "the poster child for the aspirations and failures of managed care."

This history provides three important insights for our analysis. First, the AetnaPrudential merger does not appear to raise ex ante concerns about endogeneity. There is no anecdotal evidence indicating that the merger disproportionately affected markets that were experiencing low (or high) premium growth. We corroborate this conjecture empirically below, by examining whether premium growth in the pre-merger period was systematically different in markets where both firms had significant pre-merger overlap. We also examine whether the consent decree in Texas successfully neutralized the effect of the merger in these markets; to the extent it did, we anticipate a different premium response in the affected markets. Second, our estimates will rely on a merger whose effect was short-lived, and may therefore understate the effect of typical consolidations in the industry. ${ }^{31}$ Third, the fact that Aetna eventually lost a great deal of market share post-merger suggests that post-merger quality improvements by the combined firm (if any) are not driving observed market-wide post-merger price increases. If anything, quality may have decreased, implying our estimates of the price effects of consolidation may be understated.

\section{B. The Effect of the Aetna-Prudential Merger on Market Concentration}

Immediately prior to the merger in 1999, Aetna and Prudential were the third and fifth largest insurers in our sample in terms of the number of enrollees. All 139 markets included plans offered by both firms. There was significant variation across markets, however, in the premerger shares of each firm. We hypothesize that markets served by both firms experienced increases in market concentration immediately following the merger of Aetna and Prudential,

\footnotetext{
${ }^{31}$ To the extent that Aetna and Prudential offered different products prior to the merger, the premium effects would be smaller than we would expect from a merger between more similar firms. However, in our sample the proportion of managed care plans (HMOs and POS plans) is similar for Aetna and Prudential prior to the merger.
} 
and that these increases varied by the pre-merger shares of the two firms. Specifically, for every market we calculate "simulated HHI change" ( $\left.\operatorname{sim} \Delta H H I_{m}\right)$ as follows:

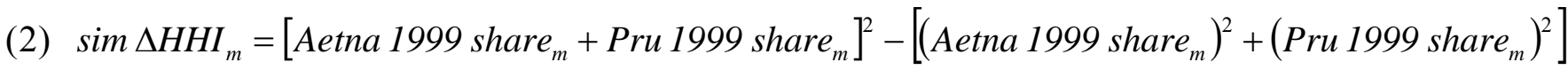

$$
\begin{aligned}
& =2 * \text { Aetna } 1999 \text { share }_{m} * \text { Pru } 1999 \text { share }_{m}
\end{aligned}
$$

$\operatorname{sim} \Delta H H I_{m}$ represents the merger-induced change in market m's HHI that would have occurred from 1999 to 2000 absent any other changes in market shares of other carriers. For example, if Aetna and Prudential were two of four firms with equal market share in 1999, $\operatorname{sim} \Delta H H I_{m}$ would equal $0.125=(0.5)^{2}-\left((0.25)^{2}+(0.25)^{2}\right)$. Figure 4 provides detail on the actual distribution of $\operatorname{sim} \Delta H H I_{m}$ in the 139 markets included in the LEHID.

We propose to use $\operatorname{sim} \Delta H H I_{m} *$ post $_{t}$, where post is an indicator variable for the postmerger years in the sample, as an instrument for $\mathrm{HHI}_{m}$. To evaluate this instrument, we estimate the following equation using market-year level data, initially excluding observations for the state of Texas:

(3) $\mathrm{HHI}_{m t}=\alpha+\lambda_{m}+\tau_{t}+\beta \operatorname{sim} \Delta H H I_{m} * \tau_{t}+\varepsilon_{\mathrm{mt}}$

The vectors denoted by $\lambda_{m}$ and $\tau_{t}$ represent a full set of market and year fixed effects, respectively. By interacting $\operatorname{sim} \Delta H H I_{m}$ with separate dummies for each year (except 1998, the omitted category), this model investigates the possibility that trends in market concentration may have been different prior to the merger in markets differentially impacted by the merger. The merger was effectively cleared in July 1999, when the Department of Justice submitted its Proposed Final Judgment. Given insurance premiums are set a few months prior to the start of the calendar year, the impact of the merger should become apparent in 2000 or later. The estimated coefficients will also determine the appropriate study period for our analysis.

Figure 5 graphs the coefficient estimates on the yearly interactions with $\operatorname{sim} \Delta H H I_{m}$, together with the 95\% confidence intervals. The sample includes data from 1998 to 2003. Estimates are presented in numerical form in column 1 of Table 4. Relative to the omitted 
interaction term, $\operatorname{sim} \Delta H H I_{m} *($ year $==1998)$, only the interactions with indicators for 2000 and 2001 are statistically significant. The coefficient estimate for $\beta$ in 1999 is small and negative $(-0.10)$, whereas estimates for $\beta$ in 2000 and 2001 are large (0.49 and 0.46 , respectively) and significant at the 5 percent level. These coefficients are significantly smaller than 1, implying that employers substituted away from Aetna and Prudential in the wake of the merger. In addition, there is likely attenuation bias due to measurement error, with some existing firms exiting and some new firms entering the sample each year.

The coefficient estimates on $\beta$ in 2002 are 2003 are both noisy and negative. These estimates reveal that the effect of the merger on market concentration declined sharply after 2001. This finding is consistent with reports from industry experts. According to a 2004 Health Affairs article by James Robinson, "[G]ossip speculates [Aetna] would be lucky to still have 30,000 of the 5 million it acquired from Prudential." As shown in the second column of Table 4, the results are qualitatively similar when we include market-specific trends.

Given the results summarized in Figure 5 and in Table 4, we focus our attention on the period from 1998 to 2001. Next, we estimate a parsimonious model that replaces the individual year interactions with a single "post" indicator that takes a value of one during 2000 and 2001:

$$
\begin{aligned}
\mathrm{HHI}_{m t} & =\alpha+\lambda_{m}+\tau_{t}+\beta_{0} \operatorname{sim} \Delta H H I_{m} * \text { post }_{t} \\
& +\left[\beta_{1} \operatorname{sim} \Delta H \mathrm{HI}_{m} * \text { post }_{t} * \text { Texas }_{m}\right]+\left[\text { post }_{t} * \text { Texas }_{m}\right]+\varepsilon_{\mathrm{mt}} .
\end{aligned}
$$

After estimating the baseline model (which excludes the terms in brackets), we add the six Texas markets to the sample and include a triple-interaction, $\operatorname{sim} \Delta H H I_{m} *$ post $_{t} *$ Texas $_{m}$, to explore whether the post-merger impact of $\operatorname{sim} \Delta H H I$ differs in these markets. We then add the term post $_{t} *$ Texas $_{m}$ to control for average changes in Texas as compared to other states during the post-period, although it may be difficult to separately identify the coefficient on the two Texas interactions because there are only 6 Texas markets and two post years.

The results are displayed in Column 3 of Table 4. As anticipated, the coefficient on $\operatorname{sim} \Delta H H I_{m} *$ post $_{t}$ is statistically significant: 0.52 , with a standard error of 0.17 . The results in Columns 4 and 5 show that the federal government achieved its objective of neutralizing the 
merger's effect on market concentration in Texas markets: the triple-interaction term for Texas markets is negative and statistically significant in both specifications, and completely offsets the impact of the merger: in both models, we cannot reject the hypothesis that the sum of the relevant double and triple-interaction terms is equal to zero. Observations from Texas may therefore constitute a useful comparison group for our later analyses involving health insurance premiums and related outcomes of interest.

To summarize, we find the merger of Aetna and Prudential resulted in significant increases in market concentration, the magnitudes of which are directly related to the degree of overlap in market shares prior to the merger. The merger-induced shocks to local concentration dissipated quickly, with no significant lingering effect by 2002. We therefore focus our analyses on the early years of our sample, duly noting the shortcomings of this narrow window of observation. Last, we find no effect of the merger on concentration within Texas markets, where the DOJ consent decree fully offset the predicted effects of the merger on market structure. Observations from Texas therefore constitute a potentially useful comparison group in our analyses involving health insurance premiums and related outcomes of interest, as they essentially allow us to conduct a "placebo test." If the change in premiums has a similar relationship with $\operatorname{sim} \Delta H H I$ in Texas as in other parts of the U.S., it suggests that some factor other than a change in insurer concentration is driving the observed relationship.

\section{The Effect of the Aetna-Prudential Merger on Health Insurance Premiums}

To investigate the effect of the merger-induced increases in local market concentration on plan premiums, we estimate models of the following form: ${ }^{32}$

$$
\begin{aligned}
\Delta \ln \left({\text { premium })_{\text {emt }}}\right. & =\alpha+\kappa_{0} \operatorname{sim} \Delta H H I_{m} * \text { post }_{t} \\
& +\mathrm{X}_{\mathrm{mt}-1} \vartheta+\Delta C_{\text {emt }}+\tau_{t}+\lambda_{m} \\
& {\left[+\varsigma_{e}\right][+\omega \Delta \text { plan type shares }} \\
& {\left[+\kappa_{1} \operatorname{sim} \Delta H H I_{m} * \text { post }_{t} * \text { Texas }_{m}\right]\left[+ \text { ppost }_{t} * \text { Texas }_{m}\right]+\varepsilon_{\text {emt }} . }
\end{aligned}
$$

\footnotetext{
${ }^{32}$ In a companion set of specifications (results available upon request), we define the outcome variable to be $\ln$ (premium) (rather than the change in this measure) and include market-level time trends. The results from those analyses are similar to those presented in this section.
} 
In light of the results from the preceding section, we focus on the period between 1998 and 2002 (i.e. annual premium growth from 1998-99, 1999-2000, 2000-01, and 2001-02). Note that in this model post $t_{t}$ takes a value of one for the 2000-2001 and 2001-2002 changes. $^{33}$ As in the OLS regressions presented in Section III, we begin with a parsimonious specification that controls for lagged market covariates and changes in employer-market characteristics, as well as fixed differences across years and markets in average premium growth (captured respectively by year and market fixed effects, denoted $\lambda_{m}$ and $\tau_{t}$ ).

The results are reported in Column 1 of Table 5. The coefficient estimate on $\operatorname{sim} \Delta H H I_{m} *$ post $_{t}$ is positive and statistically significant. Given the mean $\operatorname{sim} \Delta H H I_{m}$ of 0.014 (across all 139 geographic markets), the point estimate of 0.177 implies that, in a typical market, the merger induced an average premium increase of approximately 0.25 percent in both 2001 and 2002, and thus a total increase of 0.50 percent. The point estimate changes little upon inclusion of employer fixed effects (column 2), and as expected the standard errors decrease. Adding controls for changes in the generosity of plans (column 3) also has little impact on the point estimate, suggesting that firms did not substitute toward cheaper plan types and/or designs in the wake of the merger. We revisit these observations in section V. Here we emphasize the coefficient estimates across all specifications are similar in magnitude and precision.

Next, we study the pattern of premium growth over time by replacing the term $\operatorname{sim} \Delta H H I_{m} *$ post $_{t}$ with $\operatorname{sim} \Delta H H_{m} * \tau_{t}$ (interactions with individual year dummies, with 1998 as the omitted year). The results, in column 4, provide two key insights. First, there is no evidence of a "pre-trend" in premium growth; that is, the estimated reaction to the merger is not due to a pre-merger trend in markets with large overlapping Aetna and Prudential market shares. Second, the effect of the merger on premium growth is very similar in both "post" years.

This finding strongly suggests that the impact of the merger is appropriately modeled, i.e. that concentration affects the growth rate rather than the level of premiums. ${ }^{34}$ If the sample is extended to 2006, we find the coefficients remain of similar magnitude for two more years, and

\footnotetext{
${ }^{33}$ Recall the last year of the merger-induced HHI increase was 2001, and premiums for 2002 are set in 2001.

${ }^{34}$ An alternative explanation is that an increase in concentration does raise the level (rather than the growth rate) of premiums, but that it takes multiple years to reach the new level.
} 
then fall down to zero. ${ }^{35}$ The fact that the coefficient estimates do not become negative suggests hysteresis: consolidation results in a higher rate of premium growth, and even if circumstances change (in this case, the effect of the merger on concentration eventually disappeared) premiums remain elevated at the higher level. ${ }^{36}$

Columns 5 and 6 of Table 5 present the results of the falsification test enabled by the divestiture requirement in Texas. To execute this test, we add Texas observations to the sample and estimate the full model (as in Column 3) with the addition of a triple interaction term $\operatorname{sim} \Delta H H I_{m} *$ post $_{t} *$ Texas $_{m} \cdot{ }^{37}$ The estimated coefficient on this term will reveal whether the post-merger impact of sim $\Delta H H I$ differs in Texas markets. In fact, it is highly significant and negative (-0.24), and almost perfectly offsets the main effect of $\operatorname{sim} \Delta H H I_{m}$ in this specification (0.19). Although the result is not robust to including a separate term for post $_{t}^{*}$ Texas $_{m}$ (column 6), this is not surprising given there are only six markets in Texas and just two post years. On net, the results suggest that the market power effect of the merger in Texas was indeed neutralized by the DOJ's actions. ${ }^{38}$

\section{IV Estimates}

Table 6 presents the first-stage, reduced form, and second-stage models corresponding to our IV estimate; the reduced-form model is repeated from column 3 of Table 5. At 0.39, the estimated effect of lagged HHI on premium growth is positive, statistically significant, and roughly twice as large as the reduced form estimate. This is anticipated given the first-stage coefficient of 0.475 reported in column 1 .

\footnotetext{
${ }^{35}$ To be precise, the coefficients on interactions of the simulated change in HHI with 2003 and 2004 are 0.293 and 0.203 respectively, and are both significant with $\mathrm{p}<.01$

${ }^{36}$ As noted earlier, the results of the first stage necessitate a study period ending in 2002 . However the results just described suggest the estimates will be conservative.

${ }^{37}$ Note a second-order interaction (i.e. post $_{\mathrm{t}}{ }^{\mathrm{T}} \mathrm{Texas}_{\mathrm{m}}$ ) is arguably not appropriate in this model as market fixed effects already control for differences in annual growth rates across markets. Given the short time period and the small number of Texas markets, the coefficient on such a term would be difficult to separately identify from the triple interaction term.

${ }^{38}$ As an additional (and separate) extension of the reduced-form analysis, we examined whether the impact of the merger was greater in markets with higher initial levels of concentration. Unfortunately, coefficient estimates on $\operatorname{sim} \Delta \mathrm{HHI}_{\mathrm{m}}{ }^{*}$ post $_{\mathrm{t}} *$ initial $\mathrm{HHI}_{\mathrm{m}}$ (and variants thereof) were very imprecise.
} 
Because our estimates suggest that changes in HHI affect the growth rate (rather than just the level) of premiums, to estimate the average effect of consolidation over the entire study period, we must consider the timing of consolidation between 1998 and 2006. As previously noted, the average increase in HHI across all markets was 698 points during this period. If this increase were evenly distributed over time, the effect of consolidation on premiums during our study period would be approximately 13 percent. $^{39}$

However, an examination of our data indicates that market concentration as measured by the HHI increased more during the latter part of the study period, so applying this methodology to the actual average annual increases in HHI yields a somewhat smaller estimated cumulative increase in premiums of 7 percent. That is, the increase in premiums associated with the rise in insurer market concentration between 1998 and 2006 is approximately 7 percent. If instead one assumes that increases in concentration affect premium growth for only 2 years (rather than indefinitely), then the implied increase in premiums caused by the increase in HHI between 1998 and 2006 is somewhat lower at 5 percent. ${ }^{40}$ While both estimates are small relative to the actual increase in health insurance premiums during this same period, it suggests that consolidation raised the average annual growth rate of premiums by between 0.6 and 0.9 percentage points, which is roughly one-fourth of the difference between average annual per-capita GDP growth and the average annual growth rate in health insurance premiums during this same period.

For the sake of comparison, we also present coefficient estimates obtained using OLS models, in which lagged HHI is the predictor of interest. As noted before, OLS estimates are likely to be downward-biased, understating the actual impact of changes in market concentration on premiums. Indeed, the coefficient from the OLS model (presented in column 4) is near zero

\footnotetext{
${ }^{39}$ A uniform increase of (698/8 years) amounts to 87.25 points per year. Thus, the consolidation between 1998 and 1999 would yield an increase in premium of $\exp \left(0.008725^{*} 0.39\right.$ ) or 0.34 percent by 2000 (recall that HHI in 1999 is assumed to affect premiums in 2000, and the IV estimate is 0.39). This initial increase in HHI would also have raised premium growth between 2001 and 2002, 2002 and 2003, etc, so that by 2007 premiums are higher by $\exp \left(0.00875^{*} 0.39\right)^{\wedge} 8-1$. However, we must also incorporate the effect of the 87.25 point increase in HHI between 2000 and 2001, this same increase between 2001 and 2002, etc. The resulting estimate of 13 percent can be calculated as $\left[\prod_{n=1}^{8} \exp (n * 0.00875 * 0.39)\right]-1 \approx 13$ percent.

${ }^{40}$ The implied impact on health insurance premiums is smaller because, in this scenario, an increase in the HHI from 1998 to 1999 would only affect premium growth from 1999 to 2000 and from 2000 to 2001. Similarly, an increase in HHI from 1999 to 2000 would only affect premium growth from 2001 to 2003.
} 
(and precisely estimated). Hausman specification tests reject the null assumption of consistency for this model $(\mathrm{p}<0.01)$, underscoring the need for instrumental variables estimation.

Collectively, the results presented in this section show that consolidation does result in a "premium on health insurance premiums." We arrive at this conclusion by exploiting arguably exogenous increases in local market concentration caused by the nationwide merger between two large insurance firms, Aetna and Prudential. We show that the merger led to large and varying increases in HHI across local health insurance markets which in turn resulted in higher insurance premiums. Two key results indicate this finding is not driven by unobserved factors correlated with the pre-merger market share of Aetna and Prudential. First, there is no evidence that concentration or premiums in markets with higher sim $\Delta H H I$ were trending differently before the merger took effect. Second, we find the opposite response in Texas, where the merger was effectively blocked by the Department of Justice. These tests support the use of $\operatorname{sim} \Delta H H I_{m}$ as an instrument for lagged $\mathrm{HHI}_{m}$.

\section{Extensions}

In this section, we examine the impact of insurer consolidation on healthplan characteristics other than price, specifically the time-varying plan features that are included as controls in some prior specifications (such as plan design factor and \% HMO). For parsimony, all models are estimated on the sample including Texas (and the concomitant interaction term, post*Texas). ${ }^{41}$ We begin with plan design, the measure of plan generosity that reflects the level of copayments (among other design choices). We find that employers reduce the generosity of plan design in the wake of the Aetna-Prudential merger, and that this effect is not present in Texas markets. Thus, increasing consolidation not only leads to higher prices, holding constant observable plan characteristics such as plan design (which was controlled for in the reducedform specifications), but also to less generous insurance plans, as employers try to reduce the burden of higher insurance premiums. Note also the fact that plan design decreases post-merger is not consistent with the leading alternative explanation for post-merger price increases: quality improvements by Aetna and its competitors.

\footnotetext{
${ }^{41}$ Results change little when Texas is excluded or additional controls added.
} 
Columns 2 through 5 examine the impact of the merger on the share of employees enrolled in HMOs, POS plans, PPOs, and Indemnity plans, respectively. ${ }^{42} \mathrm{We}$ find employers in markets heavily impacted by the merger shifted away from managed care and toward PPOs and indemnity plans. Although we might have anticipated a shift toward cheaper plan types following a major consolidation, ceteris paribus, given the specifics of the merger in question these findings are unsurprising. Aetna was focused on its managed care products such as HMOs, so employers switching away from Aetna were likely to return to less-managed plans. This is also consistent with the post-merger increase in enrollment in self-insured plans (column 6), as HMOs are much more likely than other plan types to be fully-insured. It is also possible that post-merger increases in insurer market power result in especially steep premiums increases for fully-insured products, thereby driving large employers further into self-insurance. Before concluding this section, we underscore that the impact of all of these covariates on changes on premiums is controlled for in key reduced-form specifications; the results in Table 7 document whether and to what extent these covariates themselves change in response to the merger.

\section{Evaluating the Effects of Insurer Consolidation on Providers}

Thus far, we have examined the impact of market structure in the insurance industry on downstream buyers, specifically of group plans. However, the extent of competition in the insurance industry will also affect upstream suppliers, such as healthcare providers, pharmaceutical firms, and medical device manufacturers. ${ }^{43}$ To the extent suppliers have few outside options, a lack of vigorous competition among insurers may lead to monopsonistic practices. Capps (2009) reviews the theoretical and practical implications of monopsony in the context of health insurance mergers. As he notes, monopsony is the "mirror image" of monopoly: buyers pick the point on the supply curve where the marginal revenue from the incremental unit of input equals the marginal cost of purchasing that input. Assuming supply slopes upward (and the monopsonist pays one price to all suppliers), the monopsonist must pay a higher price for all inframarginal units of input in order to purchase the marginal unit. This gap

\footnotetext{
${ }^{42}$ Employers could also respond by not offering health insurance coverage. However, our data does not allow us to distinguish attrition from the sample or firm exit (e.g. due to bankruptcy or a merger) from a situation where a firm no longer offers coverage. This is unlikely to be an important employer response given that approximately 99 percent of large firms offered coverage to their workers during this period (KFF, 2009).

${ }^{43}$ In related work, Duggan and Scott Morton (2009) show that consolidation of buying power among Medicare enrollees (via Medicare Part D drug plans) leads to lower negotiated prices for drugs.
} 
between marginal revenue and marginal cost drives the monopsonist to purchase a suboptimal quantity of input, generating deadweight loss.

In this section, we consider the possibility that consolidation facilitates the exercise of monopsony power by estimating the relationship between our HHI instrument ( $\left.\operatorname{sim} \Delta H H I_{m}\right)$ and both the employment (or "quantity") and compensation (or "price") of healthcare personnel (such as physicians and nurses). As in the premium analysis, if variation in the impact of the merger on different geographic localities can be assumed orthogonal to other determinants of employment and compensation trends, our results can be interpreted as causal estimates of the impact of consolidation on these outcome measures.

Concern about insurers' monopsonistic practices has emanated not only from provider organizations (such as the American Medical Association and the American Hospital Association) but also from state and federal regulatory authorities. As previously noted, the DOJ's challenge of the Aetna-Prudential merger in two Texas markets was based in part on concern over post-merger monopsony power. The formal complaint alleged the merger "would enable Aetna to exercise monopsony power against physicians, allowing Aetna to depress physicians' reimbursement rates in Houston and Dallas, likely leading to a reduction in quantity or degradation in quality of physicians' services". ${ }^{44}$ More recently, as a precondition for the merger between UnitedHealth Group Inc. and Pacificare Health Systems Inc., the DOJ required the divestment of portions of Pacificare's commercial health insurance business in Tucson and Boulder in order to alleviate concerns about reduction in competition for physician services in those markets. ${ }^{45}$

A number of recent studies find evidence that insurer bargaining power depresses hospital prices (Feldman and Wholey 2001; Sorensen 2003; Shimazaki, Vogt and Gaynor 2008; and Ho 2009). Of these, only Feldman and Wholey explicitly consider the impact on quantity transacted, which should decline in the textbook monopsony case. They find HMOs' buying

\footnotetext{
${ }^{44}$ See Complaint, U.S. vs. Aetna Inc. (ND TX, 21 June 1999)

${ }^{45}$ See Complaint, U.S. vs. UnitedHealth Group Inc. (20 Dec 2005)
} 
power (measured by the percentage of all hospital days in its enrollment area that the HMO reimbursed) is associated with lower hospital prices, but higher utilization of hospital services. ${ }^{46}$

Our analysis complements existing research by using a different subset of the provider industry (personnel rather than hospitals), and an identification strategy that mirrors the approach for estimating the causal impact of consolidation in the downstream premium market. We supplement the LEHID data with data from the Occupational Employment Statistics (OES) survey on income and employment in healthcare-related occupations. The OES survey is conducted semi-annually and provides estimates of employment and wages in over 800 occupations representing all full-time and part-time wage and salary workers in nonfarm industries. ${ }^{47}$ The survey description specifically notes that physicians are included in the survey, apart from the 15 percent who are self-employed. Approximately 200,000 establishments are surveyed every six months, and estimates are provided by geography (MSA) and by industry.

The OES data are organized by the North American Industry Classification System (NAICS), which groups establishments into industries based on the activity in which they are primarily engaged. We restrict attention to NAICS Sector 62 - Health Care and Social Assistance - and within this sector to occupations that are classified under the Standard Occupational Classification (SOC) system as "Healthcare Practitioner and Technical Occupations." These include 43 occupation categories such as dentists, registered nurses, anesthesiologists, surgeons, and pharmacy technicians. To facilitate a comparison of impacts on physicians versus nurses, we pool together the eight occupation categories referring to physicians and the two referring to nurses. ${ }^{48}$ Nurses are by far the largest group, accounting for 56 percent of personnel in our sample; pharmacists are second (4.3 percent) and physicians are a close third (4.2 percent).

The unit of observation for this data (as well as all analyses in this section) is the occupation-MSA-year and the variables of interest are the mean annual wage and estimated

\footnotetext{
${ }^{46}$ Other studies that focus on insurer-hospital bargaining include Brooks, Dor and Wong (1997), Town and Vistnes (2001) and Capps, Dranove and Satterthwaite (2003)

${ }^{47}$ The employment and wage estimates for all occupations do not include the self-employed. The OES survey data is available online at $<$ http://www.bls.gov/OES/>

${ }^{48}$ The categories pooled under "Physicians" are Dentists, Family and General Practitioners, General Internists, Obstetricians and Gynecologists, General Pediatricians, Psychiatrists, Podiatrists and Surgeons. Some of the individual physician categories have low estimates for employment and are present in only a handful of markets in both years. The "Nurses" category includes Registered Nurses and Licensed Practical Nurses.
} 
employment. Using a crosswalk that matches MSAs to LEHID markets, we merge this data with our measures of insurer concentration (including $\operatorname{sim} \Delta H H I_{m}$ ). Table 8 provides annual summary statistics for the entire sample between 1999 and 2002, and separately for "Physicians" and "Nurses," as defined above. There is steady growth in average income over time for all occupation categories, with physicians experiencing a large jump between 2001 and $2002 .^{49}$ Nurses make up the largest employment category in the dataset by far, accounting for more than half of the estimated employment in healthcare-related occupations in all years.

We estimate parsimonious specifications using the change in log average earnings or employment between 1999 and 2002 as the dependent variable, and $\operatorname{sim} \Delta H H I_{m}$ as our main predictor:

$$
\begin{aligned}
\Delta \ln y_{\text {om }, 99-02}= & \alpha+\gamma \operatorname{sim} \Delta H H I_{m}+\omega \text { Physician }_{o} * \operatorname{sim} \Delta H H I_{m}+\text { YNurse }_{o} * \operatorname{sim} \Delta H H I_{m}+ \\
& \text { } \text { Physician }_{o}+\text { ONurse }_{o}+v \Delta \text { HospitalHHI }_{m}+\left[\Delta \ln y_{\text {om }, 97-98}+\varsigma_{o}\right]+\varepsilon_{\text {om }} .
\end{aligned}
$$

The subscripts $o$ and $m$ denote occupation and MSA, respectively. Our baseline specification includes indicators for the physician and nurse occupation categories as well as interactions between these indicators and $\operatorname{sim} \Delta H H I_{m}$. The indicators capture differences in earnings and employment growth for each category (relative to other healthcare occupations) nationwide, while the interactions reflect the differential impact of insurer consolidation on earnings and employment in these categories. In all specifications, we control for the change in hospital concentration (as measured by the HHI) in each market. As specification checks, we progressively add each of the terms in brackets. The first term, $\Delta \ln y_{\text {om,97-98 }}$, represents the change in earnings or employment between 1997 and 1998, and serves as a control for preexisting trends in earnings (or employment) growth. The second term represents a full set of fixed effects for the 35 occupation categories. We necessarily restrict the sample to occupationmarkets present in both 1999 and 2002, and we weight each observation by the average

\footnotetext{
${ }^{49}$ This is partly due to changes in the OES survey methodology between 2001 and 2002. The OES survey collects hourly wage data in 12 intervals. For survey data collected before 2001, mean wages are calculated as a weighted average of the midpoints for each interval, except for the upper open-ended wage interval, for which the minimum is used. From 2002 onward, the wage for the upper open-ended interval is estimated using data collected from the National Compensation Survey.
} 
estimated employment in that occupation-market. Standard errors are robust and clustered by market.

The results are summarized in Table 9. Columns 1 through 3 pertain to models using the change in log average earnings from 1999-2002 as the dependent variable, while columns 4-6 use the change in log employment as the dependent variable. The coefficient estimate on $\operatorname{sim} \Delta H H I_{m}$ in columns 1 through 3 is positive but imprecisely estimated, implying no significant impact of the merger on average earnings across all healthcare occupations. The coefficient on the physician indicator in columns 1 and 2 demonstrates that physicians experienced an increase of around 21 percent in average earnings between 1999 and 2002. However, the coefficient estimate on Physician $_{o} * \operatorname{sim} \Delta H H I_{m}$ is negative and significant, revealing that earnings growth for physicians was lower in markets affected by the merger. Given the average value of .014 for $\operatorname{sim} \Delta H H I_{m}$, the point estimate implies that the merger restrained growth in physician earnings by approximately 3 percent in a typical market. The coefficient on the nurse indicator reveals that nurses experienced a small decrease (around 1.5 percent on average) in earnings over the same time period. However, the interaction term for nurses is positive and statistically significant, implying this decrease was offset at least in part in markets where Aetna and Prudential had pre-merger overlap and by approximately 0.6 percent in the typical market. Changes in hospital concentration do not appear to impact earnings growth of healthcare personnel, and the results are robust to the specification checks.

Columns 4 through 6 present estimates from specifications examining the impact of the merger on employment. The coefficients are again similar across all models. Relative to other healthcare occupations, employment of physicians increased, while that of nurses decreased, during the study period. The point estimate on $\operatorname{sim} \Delta H H I_{m}$ is negative and significant: in a typical market, the merger led to a drop in healthcare-related employment of 2.7 percent. The interaction between the physician indicator and $\operatorname{sim} \Delta H H I_{m}$ is negative but noisily estimated, whereas the interaction between the nurse indicator and $\operatorname{sim} \Delta H H I_{m}$ is large, positive and significant. The relative increase in nurse employment in geographic markets differentially affected by the merger implies there was some substitution toward nurses in these markets. This explanation is buttressed by the earnings regressions, which found the merger depressed growth in physicians' earnings while modestly boosting nurses' earnings. 
As a robustness check, we estimated all models using 1999-2001 as the study period, as the BLS changed its methodology for constructing mean wages in 2002 (see the notes to Table 8 for details). Our findings are qualitatively similar. To summarize, we find that increases in market concentration predicted to occur in the wake of the Aetna-Prudential merger resulted in pronounced declines in healthcare-related employment. These declines were smaller for nurses than for other occupations on average (including physicians), and nurses also enjoyed wage increases relative to other occupations (and physicians in particular). The evidence suggests that market power facilitates the substitution of nurses for physicians. Exploring the implications of such substitution (if any) for patient outcomes is an interesting subject for future research.

Collectively, the point estimates suggest that post-merger market power restrained growth in payments made to healthcare professionals. The results are consistent with the exercise of monopsony power by insurers vis a vis healthcare workers. We caution, however, that the findings in this section and elsewhere in the paper are based on the differential impact of a single merger, albeit the largest merger to date in the health insurance industry (in terms of membership) and one with differential impacts across the 139 geographic markets in the U.S. (implying 139 small experiments).

Paired with the results of the previous section, we conclude that in markets where Aetna and Prudential had substantial pre-merger overlap, insurers were able to exercise market power simultaneously in input and output markets post-merger. Thus, the premium increases documented in the previous section likely understate the increase in insurer profits due to consolidation.

\section{Discussion and Conclusions}

Both the private and public sectors of the U.S. economy have struggled with soaring healthcare costs in recent decades. Consistent with this, the annual growth rate in employersponsored health insurance premiums has exceeded the annual growth rate in earnings by a 
factor of 7 during the last several years $(\mathrm{CEA}, 2010) .{ }^{50}$ In this study, we investigate whether and to what extent increasing consolidation in the U.S. health insurance industry is responsible for the rapid growth in employer-sponsored health insurance premiums over the past several years.

The scope of the private health insurance industry is difficult to overstate. More than 175 million non-elderly Americans are privately-insured, and this figure does not include publiclyinsured individuals whose coverage is outsourced to private insurers (as is the case for millions of Medicare and Medicaid beneficiaries). In addition, most of the elderly purchase private supplemental insurance, also known as "Medigap" plans. Finally, the recent health insurance reform legislation will substantially expand the reach of this industry, with the Congressional Budget Office projecting an increase of 15 million in the number with private insurance by 2019 (CBO, 2010).

Our research focuses on employer-sponsored group health insurance plans, which during our study period (1998-2006) accounted for slightly less than 90 percent of the privately-insured non-elderly. ${ }^{51}$ Our data includes the healthplan offerings, enrollment, and premiums for an unbalanced panel of more than 800 large U.S. employers, and appears to be fairly representative of large employers nationwide. We include both fully-insured and self-insured plans in our analysis, as both options are viable for the firms in our sample.

We arrive at four main conclusions. First, most Americans live in markets dominated by a small number of insurers, and most markets are becoming more concentrated over time. We estimate that the fraction of local markets falling under the "highly concentrated" category (per the Department of Justice's Horizontal Merger Guidelines) increased from 68 to 99 percent between 1998 and 2006. Second, premiums are not rising more quickly in markets experiencing the greatest increases in concentration, even controlling for a rich set of observable characteristics of plans.

\footnotetext{
${ }^{50}$ Data from the BLS "Employer Costs for Employee Compensation" survey indicate that the annual growth rate in workers' real average hourly wage and salary income increased by 0.7 percent annually from 2000 to 2009. During that same period, the growth rate in ESI premiums was substantially higher at 5.1 percent per year (CEA, 2010).

${ }^{51}$ Source: EBRI Issue Brief, October 2007; Kaiser/HRET Survey of Employer Sponsored Health Benefits, 2007, Exhibit 10.1 .
} 
Third, when we account for the fact that changes in concentration are not orthogonal to other determinants of premium growth, we find that increases in concentration do raise premiums. Our instrumental variables estimates, which exploit plausibly exogenous shocks to local market structure generated by the 1999 merger of Aetna and Prudential, imply the average market-level changes in HHI between 1998 and 2006 resulted in a total premium increase of approximately 7 percentage points by 2007, ceteris paribus. Of course, to the extent these increases stimulated substitution toward cheaper products, the realized increase may have been smaller. We emphasize, however, that the 7 percent figure may be understated due to the short "post" period in our analysis.

Fourth, we find evidence that consolidation results in lower employment of healthcare workers, and may facilitate the substitution of nurses for physicians. Using data from the Occupational Employment Statistics survey between 1999 and 2002, we find the AetnaPrudential merger reduced physician earnings in a typical market by 3 percent and raised nurse earnings 0.6 percent. Of course, these magnitudes were amplified in markets with larger premerger market shares of Aetna and Prudential. ${ }^{52}$

Our results confirm that Americans are indeed paying a premium on their health insurance premiums as a result of recent increases in the concentration of this industry. However, consolidation explains very little of the steep increase in health insurance premiums in recent years. While 7 percent is large in absolute terms - it translates into approximately \$34 billion in extra annual premiums ${ }^{53}$ - it pales in comparison to the 60 percent increase in average, inflation-adjusted premiums observed for the average firm in our sample during the same 19982006 time period. These findings do not necessarily imply insurance markets are competitive, however, only that consolidation in recent years has not been the driving force behind the rapid growth in private health insurance premiums. The industry was sufficiently concentrated even before the recent wave of consolidations to - at least in theory - sustain supra-competitive prices. To the extent insurance carriers behaved as a "disciplined" oligopoly by the late 1990s, there may have been little room to optimally raise premiums in the wake of further consolidation.

\footnotetext{
${ }^{52}$ To be more precise, the market shares need to be large and overlapping. The predicted change in local market HHI associated with the merger equals $2 *$ Aetna share * Prudential share. See equation 2 for the derivation.

${ }^{53}$ This calculation uses the 1998 level of private health expenditures ( $\$ 490$ billion in 2007 dollars). This figure may understate the aggregate effect of consolidation on profits as it does not include the decrease in provider payments attained through the exercise of monopsony power.
} 
Finally, we note that 7 percent is a large figure compared to the operating margins of insurers, which are typically less than 5 percent. ${ }^{54}$ While it is beyond the scope of this paper to assess the welfare implications of the earnings and employment effects we document, we note these findings confirm the exercise of monopsonistic power in some markets.

We caution that our analysis relies on a single merger, albeit one that effectively generated 139 experiments (one per geographic market) that we exploit to generate our estimates. Additional research that utilizes other plausibly exogenous sources of variation in market structure would be invaluable to assessing conduct in this important industry. We also emphasize that our sample consists primarily of large, multisite firms, and the results may not be generalizeable to all market segments, including the small group and individual markets. ${ }^{55}$ Finally, there has also been a great deal of consolidation across (as opposed to within) markets, and the effects of such consolidation are not reflected in our estimates.

\footnotetext{
${ }^{54}$ Citing research by Sanford Bernstein, an investment research firm, The Economist reported that 2003 operating margins were 5.1 percent, "possibly an all-time high" as of the time of reporting (6/12/2004, p. 71). Insurers derive a sizeable share of total profits (which exceed operating margins) via the float: they earn interest on premium dollars before they are paid to reimburse claims.

${ }^{55}$ High and increasing concentration has also been documented in the individual/small group market. For details, see "Private Health Insurance: Research on Competition in the Insurance Industry," a GAO Report dated 7/31/2009 and available online at $<\mathrm{http} / /$ www.gao.gov/products/GAO-09-864R $>$.
} 


\section{References}

"Competition in Health Insurance: A Comprehensive Study of U.S. Markets," a report by the American Medical Association, 2007.

"Private Health Insurance: Research on Competition in the Insurance Industry", a report by the United States Government Accountability Office, 2009.

Berry, S. and Waldfogel, J. 2001. “Do Mergers Increase Product Variety?”, Quarterly Journal of Economics, 116(3): 1009-1025.

Borenstein, S. and Rose, N. 1994. "Competition and Price Dispersion in the U.S. Airline Industry”, Journal of Political Economy, 102, 653-683

Bresnahan, T. 1989. "Empirical Studies in Industries with Market Power”, Handbook of Industrial Organization, Vol. II, edited by Richard Schmalensee and Robert Willig

Brooks, J.M., Dor, A. and Wong, H.S. 1997. "Hospital-insurer Bargaining: an Empirical Investigation of Appendectomy Pricing', Journal of Health Economics, 16(4), 417-434

Capps, C.S., 2009. "Buyer Power in Health Plan Mergers," Journal of Competition Law and Economics, forthcoming.

Capps, C.S., Dranove, D. and Satterthwaite, M. 2003. 'Competition and Market Power in Option Demand Markets', Rand Journal of Economics, 34(4): 737-763.

Congressional Budget Office. 2010. "Estimate of Direct Spending and Revenue Effects for the Amendment in the Nature of a Substitute Released on March 18,2010." Available at: http://www.cbo.gov/ftpdocs/113xx/doc11355/hr4872.pdf

Cotterill, R. 1986. "Market Power in the Retail Food Industry: Evidence from Vermont", Review of Economics and Statistics, 68(3), 379-386

Council of Economic Advisers. 2010. "Exploring the Link Between Rising Health Insurance Premiums and Stagnant Wages." Available at:

http://www.whitehouse.gov/blog/2010/03/12/exploring-link-between-rising-health-insurancepremiums-and-stagnant-wages

Cuellar, A. and Gertler, P. 2006. "Strategic integration of hospitals and physicians", Journal of Health Economics, 25(1):1-28.

Cutler, D., McClellan, M. and Newhouse, J. 2000. “How Does Managed Care Do It?”, RAND Journal of Economics, 31(3), 526-548.

Dafny, L. 2009. "Estimation and Identification of Merger Effects: An Application to Hospital Mergers," Journal of Law \& Economics, 52(3): 523-440. 
Dafny, L. 2010. “Are Health Insurance Markets Competitive?” NBER WP 14572, forthcoming in The American Economic Review

Davis, P. 2005. "The Effect of Local Competition on Admission Prices in the U.S. Motion Picture Exhibition Market", Journal of Law and Economics, 48, 677-708

Demsetz, H. 1973. "Industry Structure, Market Rivalry and Public Policy", Journal of Law and Economics, 16, 1-9

Duggan, M. and Scott Morton, F. 2010. "The Effect of the Medicare Drug Benefit on Pharmaceutical Prices and Utilization", American Economic Review. March.

Evans, W., Froeb, L. and Werden, G., 1993, "Endogeneity in the Concentration-Price Relationship: Causes, Consequences and Cures", Journal of Industrial Economics, 41(4), 431438

Feldman, R. and Wholey, D. 1996. "Effect of mergers on HMO premiums", Health Care Financing Review, 17(3), 171-190

Feldman, R. and Wholey, D., 2001. “Do HMOs have monopsony power?”, International Journal of Health Care Finance and Economics, 1, 7-22.

Hannan, T. 1992. “The Functional Relationship Between Prices and Market Concentration: The Case of the Banking Industry", Empirical Studies in Industrial Organization: Essays in Honor of Leonard Weiss, 35-59

Hastings, J. and Gilbert, R. 2005. "Market Power, Vertical Integration and the Wholesale Price of Gasoline", The Journal of Industrial Economics, 13(4), 469-492

Ho, K. 2009." Insurer Provider Networks in the Medical Care Market", The American Economic Review, 99(1): 393-430.

Hortacsu, A. and Syverson, C. 2007. "Cementing Relationships: Vertical Integration, Foreclosure, Productivity, and Prices,” Journal of Political Economy, 115(2), 250-301

Kim, E.H. and Singhal, V. 1993. "Mergers and Market Power: Evidence from the Airline Industry," American Economic Review, 83(3), 549-569

Manuszak, M. and Moul, C. 2008. "Prices and Endogenous Market Structure in Office Supply Superstores", The Journal of Industrial Economics, 56, 94-112

Mazzeo, M. 2002. “Competitive Outcomes in Product-Differentiated Oligopoly”, Review of Economics and Statistics, 84(4), 716-728

Morrison, S. and Winston, C. 1990. "The Dynamics of Airline Pricing and Competition", American Economics Review (Papers \& Proceedings), 80, 2, 389-393

Newmark, C. 1990. "A New Test of the Price-Concentration Relationship in Grocery Retailing”, Economic Letters, 33, 369-373 
Newmark, C. 2004. "Price Concentration Studies: There You Go Again”, Manuscript prepared for the DOJ/FTC Workshop

Robinson, J. 2004. "Consolidation and the Transformation of Competition in Health Insurance", Health Affairs, 23(6), 11-24

Scanlon, Dennis P., Chernew, Michael, and Woolton Lee. 2006. "Competition in Health Insurance Markets: Limitations of Current Measures for Policy Analysis," Medical Care Research and Review, 63(6): 37S-55S.

Scanlon, D., Swaminathan, S., Lee, W. and Chernew, M. 2008. "Does Competition Improve Health Care Quality?", Health Services Research, 43(6), 1931-1951

Shimazaki, A., Vogt, W. and Gaynor, M. 2008. "Hospital Prices and Market Structure in the Hospital and Insurance Industries”, Working Paper, Carnegie Mellon University

Sorensen, A.T. 2003. 'Insurer-Hospital Bargaining: Negotiated Discounts in Post-Deregulation Connecticut', Journal of Industrial Economics, 51(4), 469-490

Singh, V. and Zhu, T. 2006. "Pricing and Market Concentration in Oligopoly Markets", Mimeo, Carnegie Mellon University.

Town, R. 2001. “The Welfare Impact of HMO Mergers”, Journal of Health Economics, 20, 967994

Town, R. and Vistnes, G. 2001. 'Hospital Competition in HMO Networks', Journal of Health Economics, 20(4), 733-753

U.S. Census Bureau. 2009. "Income, Poverty, and Health Insurance Coverage." Available at: http://www.census.gov/prod/2009pubs/p60-236.pdf.

Weiss, L. 1989. “Concentration and Price”, MIT Press.

Wholey, D., Feldman, R. and Christianson, J.B. 1995. "The Effect of Market Structure on HMO Premiums", Journal of Health Economics, 14, 81-105 
Figure 1. Nationwide Four Firm Concentration Ratio, 1998-2006

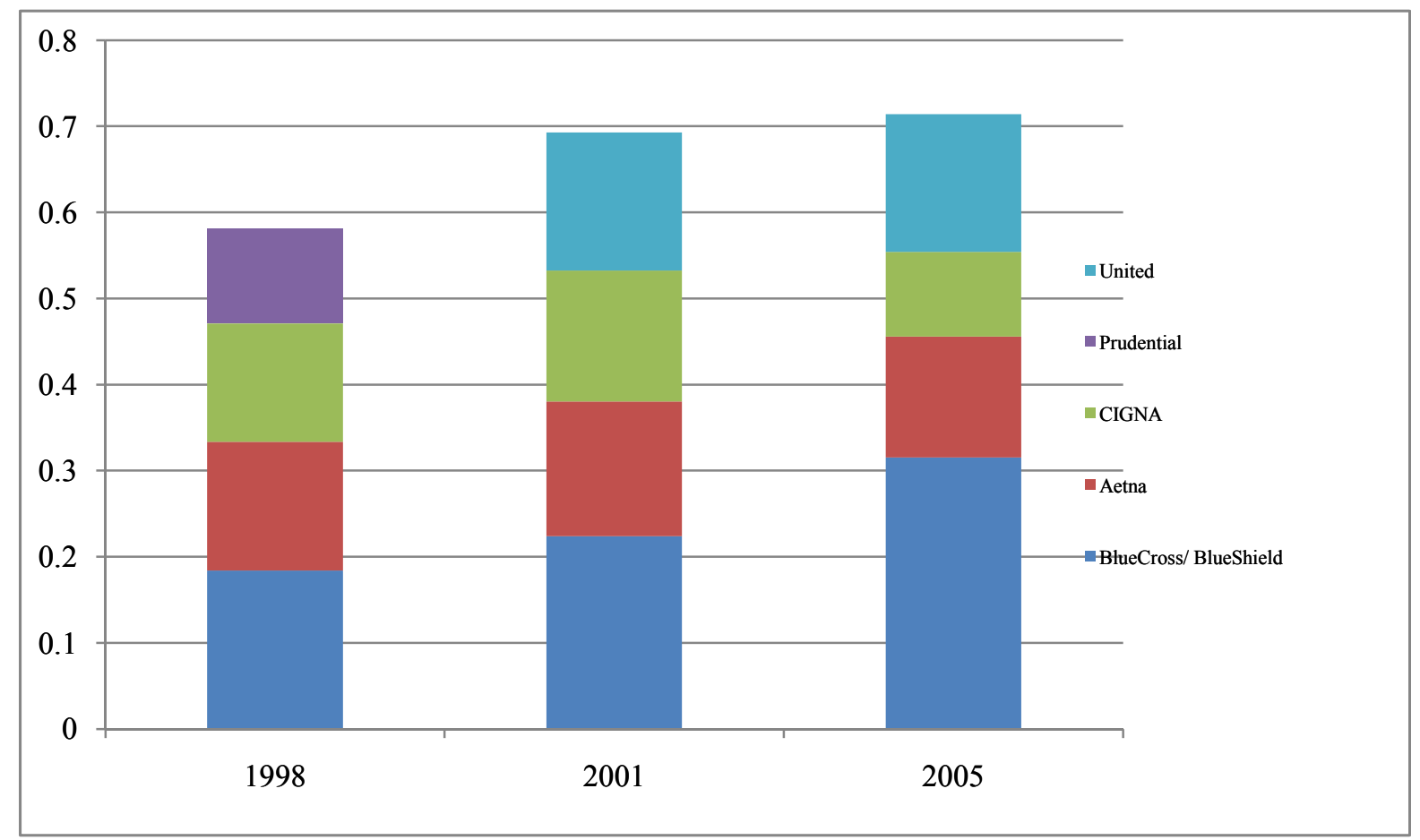

Note: Market shares are computed using the Large Employer Health Insurance Dataset, described in the text, and may not be generalizable to the insurance industry at large. 
Figure 2. Change in Local Market Herfindahl
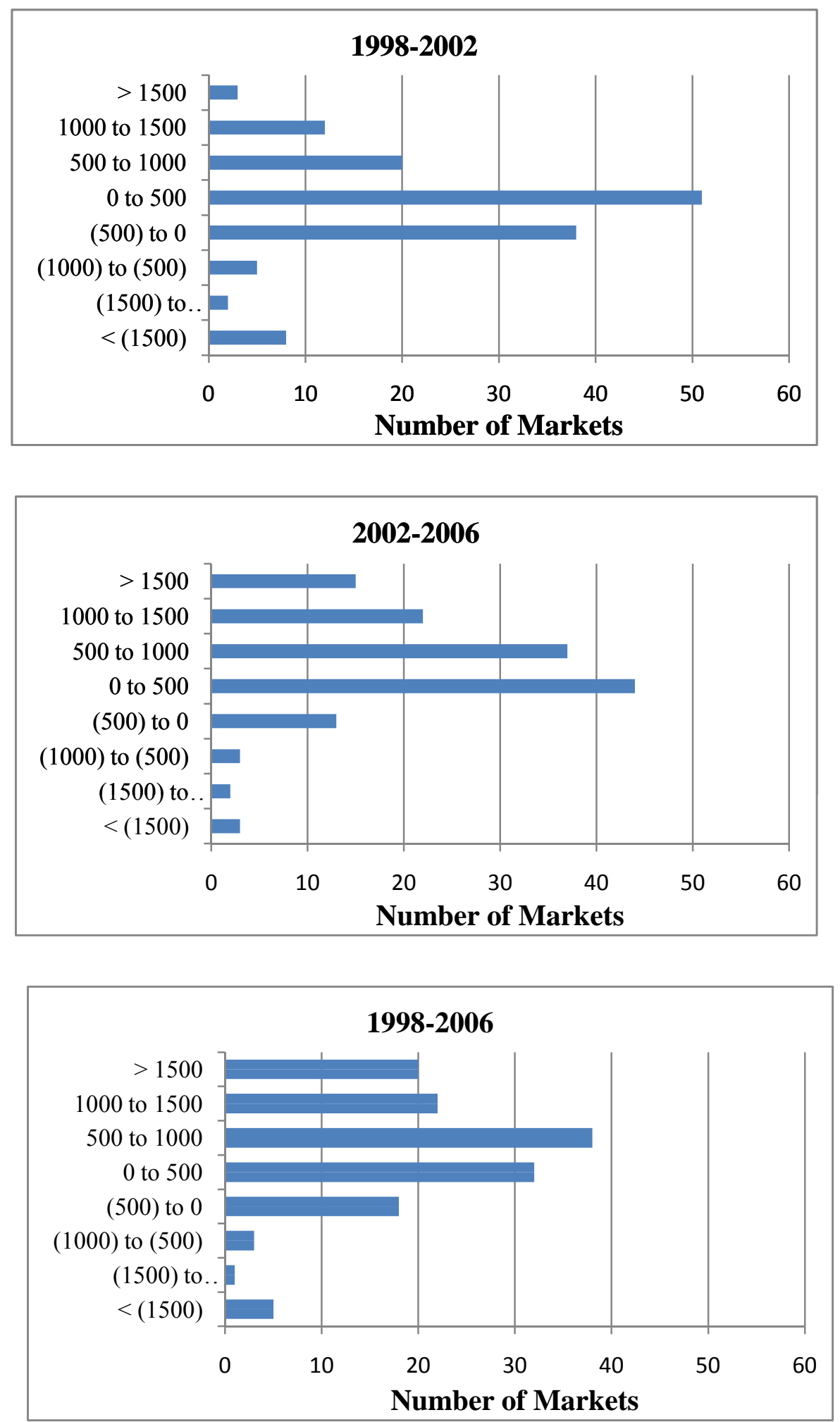
Figure 3. Change in Number of Carriers per Market
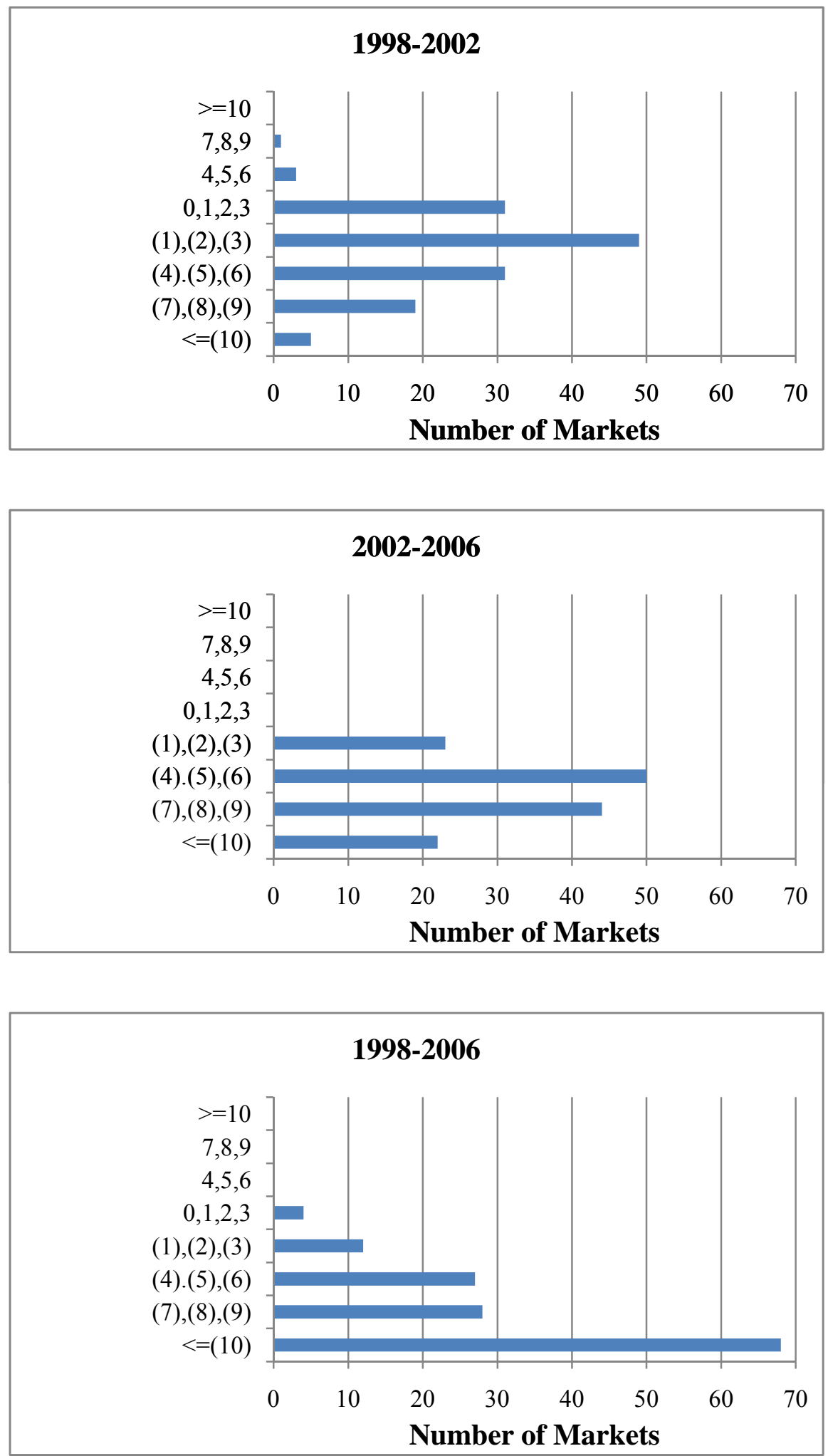
Figure 4. Distribution of Simulated Change in HHI Resulting from Aetna-Prudential Merger

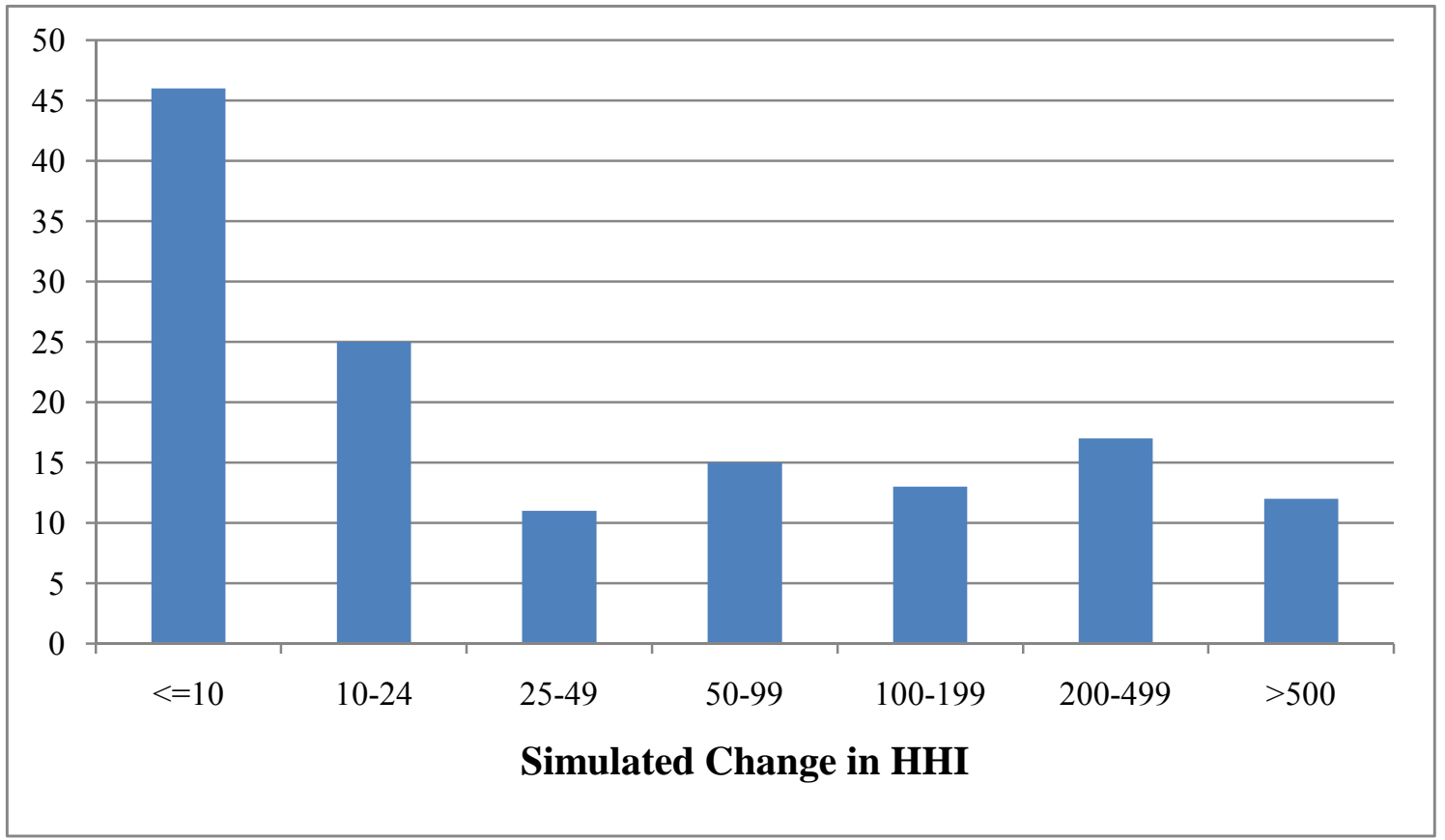

Note: $\mathrm{HHI}$ is scaled from 0 to 10,000 
Figure 5. Estimated Coefficients from Regression of HHI on Simulated Change in HHI

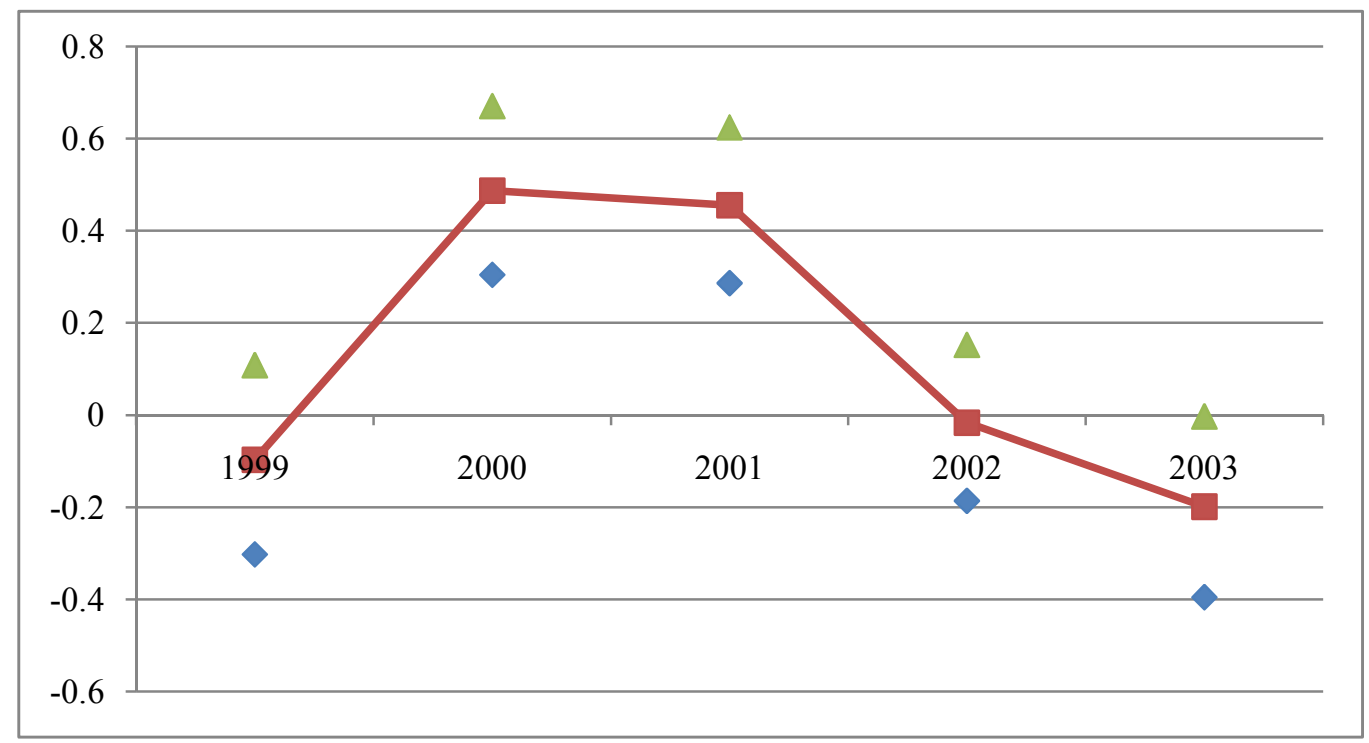

Note: Coefficient estimates and 95\% confidence intervals obtained from Column 1 of Table 4. 
Table 1. Descriptive Statistics

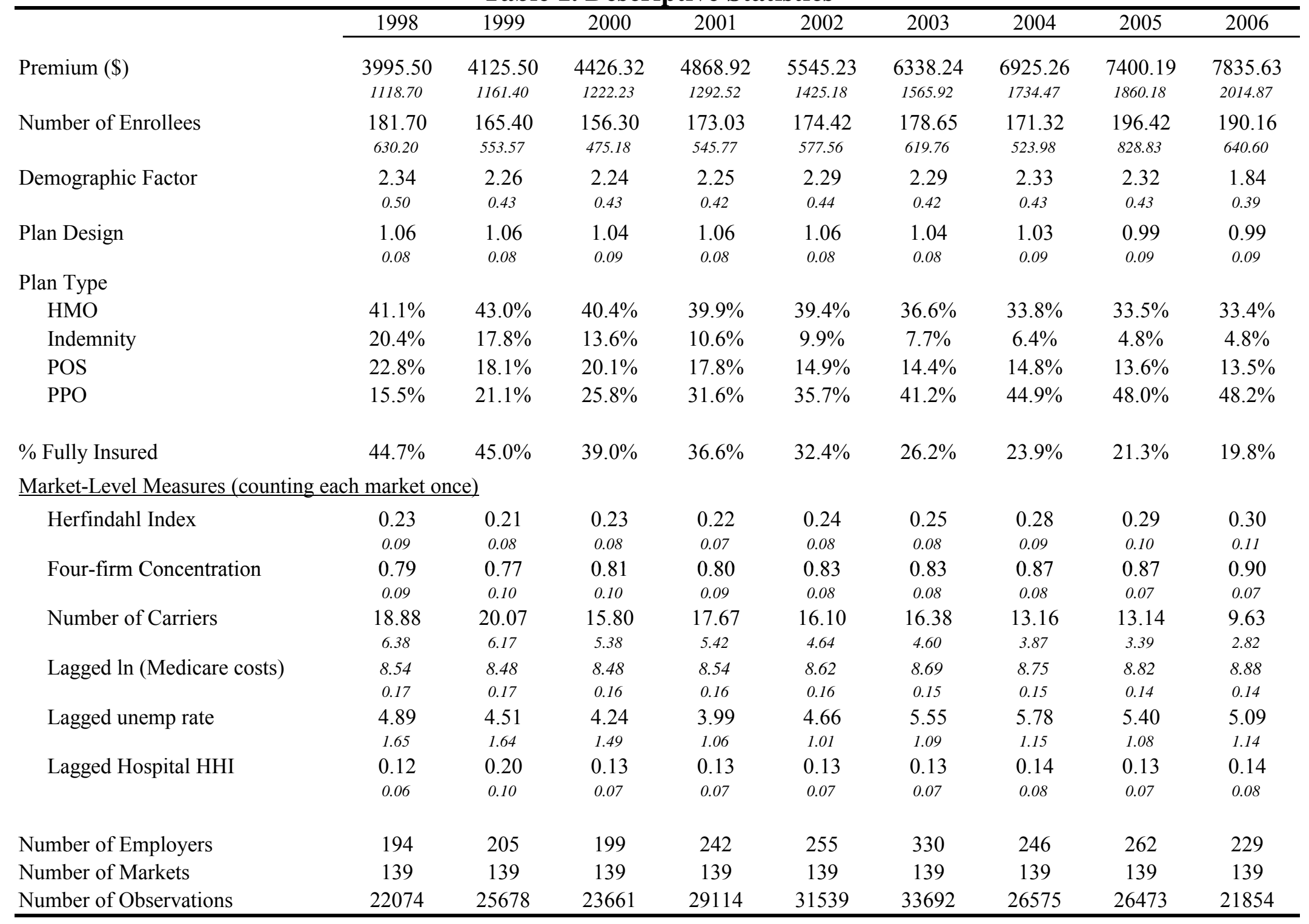

Notes: All statistics are unweighted. The unit of observation is an employer-carrier-market-plantype-year combination, unless noted otherwise. Demographic factor reflects age, gender, and family size for enrollees. Plan design measures the generosity of benefits. Both are constructed by the data source and exact formulae are not available. Premiums are in nominal dollars.. Standard deviations are in italics. 
Table 2. Descriptive Statistics (Unit of Observation: Employer-Market-Year)

\begin{tabular}{|c|c|c|c|c|c|c|c|c|c|}
\hline & 1998 & 1999 & 2000 & 2001 & 2002 & 2003 & 2004 & 2005 & 2006 \\
\hline \multirow[t]{2}{*}{ Premium (\$) } & 4104.47 & 4185.45 & 4495.88 & 4914.50 & 5624.70 & 6443.94 & 6980.52 & 7455.44 & 7832.46 \\
\hline & 1047.76 & 1019.94 & 1100.30 & 1184.72 & 1280.61 & 1423.89 & 1583.40 & 1727.21 & 1807.98 \\
\hline \multirow[t]{2}{*}{ Number of Enrollees } & 399.86 & 368.17 & 333.68 & 364.29 & 370.42 & 368.85 & 334.76 & 371.10 & 361.47 \\
\hline & 1465.47 & 1289.57 & 1111.06 & 1303.26 & 1397.66 & 1317.26 & 1030.86 & 1803.23 & 1245.86 \\
\hline \multirow[t]{2}{*}{ Demographic Factor } & 2.35 & 2.27 & 2.26 & 2.26 & 2.29 & 2.32 & 2.34 & 2.33 & 1.84 \\
\hline & 0.47 & 0.40 & 0.40 & 0.40 & 0.41 & 0.40 & 0.40 & 0.41 & 0.38 \\
\hline \multirow[t]{2}{*}{ Plan Design } & 1.05 & 1.05 & 1.03 & 1.05 & 1.05 & 1.04 & 1.02 & 0.98 & 0.98 \\
\hline & 0.06 & 0.06 & 0.06 & 0.06 & 0.06 & 0.06 & 0.07 & 0.07 & 0.07 \\
\hline \multicolumn{10}{|l|}{ Plan Type } \\
\hline HMO & $29.4 \%$ & $32.8 \%$ & $30.6 \%$ & $29.6 \%$ & $30.6 \%$ & $28.7 \%$ & $25.8 \%$ & $25.1 \%$ & $25.4 \%$ \\
\hline Indemnity & $22.4 \%$ & $17.2 \%$ & $12.2 \%$ & $8.8 \%$ & $7.2 \%$ & $5.0 \%$ & $3.9 \%$ & $2.2 \%$ & $2.8 \%$ \\
\hline POS & $28.1 \%$ & $22.3 \%$ & $24.6 \%$ & $20.1 \%$ & $16.8 \%$ & $16.2 \%$ & $16.3 \%$ & $15.1 \%$ & $14.1 \%$ \\
\hline PPO & $20.0 \%$ & $27.7 \%$ & $32.6 \%$ & $41.6 \%$ & $45.4 \%$ & $50.0 \%$ & $54.0 \%$ & $57.6 \%$ & $57.6 \%$ \\
\hline$\%$ Fully Insured & $33.0 \%$ & $35.5 \%$ & $30.0 \%$ & $27.4 \%$ & $24.2 \%$ & $19.5 \%$ & $17.1 \%$ & $14.9 \%$ & $14.4 \%$ \\
\hline Number of Observations & 10033 & 11536 & 11086 & 13829 & 14851 & 16318 & 13600 & 14012 & 11497 \\
\hline
\end{tabular}

Notes: All statistics are unweighted. The unit of observation is an employer-market-year combination. Demographic factor reflects age, gender, and family size for enrollees. Plan design measures the generosity of benefits. Both are constructed by the data source and exact formulae are not available. Premiums are in nominal dollars.Standard deviations are in italics. 
Table 3. Effect of Consolidation on Premiums (OLS Models)

Study Period: 1998-2006

\begin{tabular}{|c|c|c|c|}
\hline & \multicolumn{3}{|c|}{ Dependent Variable = Annual Change in In(Premiums) } \\
\hline & (1) & (2) & (3) \\
\hline Lagged HHI & $\begin{array}{l}0.0015 \\
(0.0099)\end{array}$ & $\begin{array}{c}-0.0036 \\
(0.0094)\end{array}$ & $\begin{array}{c}-0.0052 \\
(0.0092)\end{array}$ \\
\hline \multicolumn{4}{|l|}{ Market-Year Controls } \\
\hline Lagged $\ln ($ Medicare costs per cap) & $\begin{array}{c}-0.0151 \\
(0.0162)\end{array}$ & $\begin{array}{c}-0.0196 \\
(0.0161)\end{array}$ & $\begin{array}{c}-0.0189 \\
(0.0161)\end{array}$ \\
\hline Lagged Unemp rate & $\begin{array}{l}0.1178 \\
(0.0975)\end{array}$ & $\begin{array}{l}0.1469 \\
(0.0899)\end{array}$ & $\begin{array}{c}0.1575^{*} \\
(0.0915)\end{array}$ \\
\hline Lagged Hospital HHI & $\begin{array}{l}0.0078 \\
(0.0156)\end{array}$ & $\begin{array}{c}-0.0026 \\
(0.0146)\end{array}$ & $\begin{array}{l}0.0009 \\
(0.0146)\end{array}$ \\
\hline \multicolumn{4}{|l|}{ Employer-market controls } \\
\hline$\Delta$ Demographic factor & $\begin{array}{c}0.3031 * * * \\
(0.0042)\end{array}$ & $\begin{array}{c}0.3139 * * * \\
(0.0041)\end{array}$ & $\begin{array}{c}0.3112 * * * \\
(0.0041)\end{array}$ \\
\hline$\Delta$ Fraction of Self Insured Employees & $\begin{array}{c}0.0277 * * * \\
(0.0047)\end{array}$ & $\begin{array}{c}0.0317 * * * \\
(0.0048)\end{array}$ & $\begin{array}{c}0.0240 * * * \\
(0.0038)\end{array}$ \\
\hline$\Delta$ Plan Design & & & $\begin{array}{c}0.3488 * * * \\
(.0215)\end{array}$ \\
\hline$\Delta$ Fraction in Indemnity Plans & & & $\begin{array}{c}0.0851 * * * \\
(.0056)\end{array}$ \\
\hline$\Delta$ Fraction in HMO Plans & & & $\begin{array}{c}-0.0522 * * * \\
\quad(.0062)\end{array}$ \\
\hline$\Delta$ Fraction in PPO Plans & & & $\begin{array}{c}0.0018 \\
(.003)\end{array}$ \\
\hline Employer FE & No & Yes & Yes \\
\hline Number of Observations & 66906 & 66906 & 66906 \\
\hline
\end{tabular}

Notes: The unit of observation is the employer-market-year. All specifications include market and year fixed effects. HHI is scaled from 0 to 1.Standard errors are clustered by market. 
Table 4. Effect of the Aetna-Prudential Merger on Market Concentration

Dependent Variable $=$ HHI

\begin{tabular}{|c|c|c|c|c|c|}
\hline & $\begin{array}{c}(1) \\
1998-2003\end{array}$ & $\begin{array}{c}(2) \\
1998-2003\end{array}$ & $\begin{array}{c}(3) \\
1998-2001\end{array}$ & $\begin{array}{c}(4) \\
1998-2001\end{array}$ & $\begin{array}{c}(5) \\
1998-2001\end{array}$ \\
\hline $\operatorname{Sim} \Delta \mathrm{HHI} *($ Year $==1999)$ & $\begin{array}{c}-0.097 \\
(0.180)\end{array}$ & & & & \\
\hline $\operatorname{Sim} \Delta \mathrm{HHI} *($ Year $==2000)$ & $\begin{array}{c}0.487 * * \\
(0.204)\end{array}$ & $\begin{array}{c}0.681 * \\
(0.396)\end{array}$ & & & \\
\hline $\operatorname{Sim} \Delta \mathrm{HHI} *($ Year $==2001)$ & $\begin{array}{c}0.455 * * \\
(0.194)\end{array}$ & $\begin{array}{l}0.745 \\
(0.505)\end{array}$ & & & \\
\hline $\operatorname{Sim} \Delta \mathrm{HHI} *($ Year $==2002)$ & $\begin{array}{l}-0.017 \\
(0.205)\end{array}$ & $\begin{array}{l}0.370 \\
(0.728)\end{array}$ & & & \\
\hline $\operatorname{Sim} \Delta \mathrm{HHI} *($ Year $==2003)$ & $\begin{array}{l}-0.199 \\
(0.248)\end{array}$ & $\begin{array}{l}0.284 \\
(0.938)\end{array}$ & & & \\
\hline $\operatorname{Sim} \Delta \mathrm{HHI} *($ Year $>=2000)$ & & & $\begin{array}{c}0.520 * * * \\
(0.166)\end{array}$ & $\begin{array}{c}0.512 * * * \\
(0.165)\end{array}$ & $\begin{array}{c}0.520 * * * \\
(0.166)\end{array}$ \\
\hline $\operatorname{Sim} \Delta \mathrm{HHI} *($ Year $>=2000) *($ Texas $==1)$ & & & & $-0.646 * * *$ & $-1.262 * * *$ \\
\hline Texas $*($ Year $>=2000)$ & & & & $(0.224)$ & $\begin{array}{c}(0.291) \\
0.052 * * * \\
(0.019)\end{array}$ \\
\hline Texas included? & No & No & No & Yes & Yes \\
\hline \# Observations & 798 & 798 & 532 & 556 & 556 \\
\hline R-squared & 0.677 & 0.809 & 0.674 & 0.677 & 0.678 \\
\hline
\end{tabular}

Notes: The unit of observation is the market-year. All specifications include market and year fixed effects. HHI is scaled from 0 to 1 . Standard errors are clustered by market.

*** signifies $p<.01, * *$ signifies $p<.05$, * signifies $p<.10$ 
Table 5. Merger Effects on Premiums

Study Period: 1998-2002

\begin{tabular}{|c|c|c|c|c|c|c|}
\hline & \multicolumn{6}{|c|}{ Dependent Variable = Annual Change in $\ln ($ Premiums) } \\
\hline & (1) & $(2)$ & (3) & (4) & $(5)$ & (6) \\
\hline $\operatorname{Sim} \Delta \mathrm{HHI} *($ Year $>=2001)$ & $\begin{array}{c}0.1774 * * * \\
(0.0558)\end{array}$ & $\begin{array}{c}0.2022 * * * \\
(0.0484)\end{array}$ & $\begin{array}{c}0.1859 * * * \\
(0.0499)\end{array}$ & & $\begin{array}{c}0.1929 * * * \\
(0.0490)\end{array}$ & $\begin{array}{c}0.1884 * * * \\
(0.0491)\end{array}$ \\
\hline Sim $\Delta$ HHI $*($ Year $==2000)$ & & & & $\begin{array}{l}0.0107 \\
(0.0611)\end{array}$ & & \\
\hline $\operatorname{Sim} \Delta \mathrm{HHI} *($ Year $==2001)$ & & & & $\begin{array}{c}0.1812^{* *} \\
(0.0713)\end{array}$ & & \\
\hline $\operatorname{Sim} \Delta \mathrm{HHI} *($ Year $==2002)$ & & & & $\begin{array}{c}0.1996^{* * *} \\
(0.0670)\end{array}$ & & \\
\hline $\operatorname{Sim} \Delta \mathrm{HHI} *($ Year $>=2001) *($ Texas $==1)$ & & & & & $\begin{array}{c}-0.2375^{* * *} \\
(0.0686)\end{array}$ & $\begin{array}{l}-0.0561 \\
(0.1909)\end{array}$ \\
\hline$($ Year $>=2001) *($ Texas $==1)$ & & & & & & $\begin{array}{l}0.0157 \\
(0.0165)\end{array}$ \\
\hline \multicolumn{7}{|l|}{ Market-Year Controls } \\
\hline Lagged $\ln$ (Medicare costs per cap) & $\begin{array}{c}-0.0291 \\
(0.0344)\end{array}$ & $\begin{array}{c}-0.0472 \\
(0.0359)\end{array}$ & $\begin{array}{c}-0.0389 \\
(0.0355)\end{array}$ & $\begin{array}{c}-0.0397 \\
(0.0363)\end{array}$ & $\begin{array}{c}-0.0455 \\
(0.0331)\end{array}$ & $\begin{array}{c}-0.0475 \\
(0.0328)\end{array}$ \\
\hline Lagged Unemp rate & $\begin{array}{c}0.4793 * * * \\
(0.1740)\end{array}$ & $\begin{array}{c}0.5788^{* * * *} \\
(0.1613)\end{array}$ & $\begin{array}{c}0.5672 * * * \\
\quad(0.1550)\end{array}$ & $\begin{array}{c}0.5698 * * * \\
(0.1554)\end{array}$ & $\begin{array}{c}0.5752 * * * \\
(0.1517)\end{array}$ & $\begin{array}{c}0.5346^{* * *} \\
(0.1516)\end{array}$ \\
\hline Lagged Hospital HHI & $\begin{array}{l}0.0025 \\
(0.0219)\end{array}$ & $\begin{array}{c}-0.0036 \\
(0.0206)\end{array}$ & $\begin{array}{l}0.0025 \\
(0.0204)\end{array}$ & $\begin{array}{l}0.0025 \\
(0.0204)\end{array}$ & $\begin{array}{c}-0.0102 \\
(0.0204)\end{array}$ & $\begin{array}{c}-0.0084 \\
(0.0202)\end{array}$ \\
\hline \multicolumn{7}{|l|}{ Employer-market controls } \\
\hline$\Delta$ Demographic factor & $\begin{array}{c}0.3040 * * * \\
(0.0059)\end{array}$ & $\begin{array}{c}0.3278 * * * \\
(0.0054)\end{array}$ & $\begin{array}{c}0.3226 * * * \\
\quad(0.0055)\end{array}$ & $\begin{array}{c}0.3226 * * * \\
\quad(0.0055)\end{array}$ & $\begin{array}{c}0.3243 * * * \\
\quad(0.0054)\end{array}$ & $\begin{array}{c}0.3243 * * * \\
(0.0054)\end{array}$ \\
\hline$\Delta$ Fraction of Self Insured Employees & $\begin{array}{c}0.0482 * * * \\
(0.0068)\end{array}$ & $\begin{array}{c}0.0541 * * * \\
(0.0068)\end{array}$ & $\begin{array}{c}0.0187 * * * \\
(0.0058)\end{array}$ & $\begin{array}{c}0.0187 * * * \\
(0.0058)\end{array}$ & $\begin{array}{c}0.0169 * * * \\
(0.0055)\end{array}$ & $\begin{array}{c}0.0169 * * * \\
(0.0055)\end{array}$ \\
\hline$\Delta$ Plan Design & & & $\begin{array}{c}0.2234 * * * \\
\quad(0.0402)\end{array}$ & $\begin{array}{c}0.2234 * * * \\
(0.0402)\end{array}$ & $\begin{array}{c}0.2103 * * * \\
(0.0404)\end{array}$ & $\begin{array}{c}0.2105 * * * \\
\quad(0.0403)\end{array}$ \\
\hline$\Delta$ Fraction in Indemnity Plans & & & $\begin{array}{c}0.0892 * * * \\
(0.0077)\end{array}$ & $\begin{array}{c}0.0892 * * * \\
(0.0077)\end{array}$ & $\begin{array}{c}0.0913 * * * \\
(0.0076)\end{array}$ & $\begin{array}{c}0.0913 * * * \\
(0.0076)\end{array}$ \\
\hline$\Delta$ Fraction in HMO Plans & & & $\begin{array}{c}-0.0806 * * * \\
(0.0089)\end{array}$ & $\begin{array}{c}-0.0806 * * * \\
(0.0089)\end{array}$ & $\begin{array}{c}-0.0844 * * * \\
(0.0085)\end{array}$ & $\begin{array}{c}-0.0844 * * * \\
(0.0085)\end{array}$ \\
\hline$\Delta$ Fraction in PPO Plans & & & $\begin{array}{l}0.0004 \\
(0.0062)\end{array}$ & $\begin{array}{l}0.0004 \\
(0.0062)\end{array}$ & $\begin{array}{c}-0.0014 \\
(0.0059)\end{array}$ & $\begin{array}{c}-0.0014 \\
(0.0059)\end{array}$ \\
\hline Employer FE & No & Yes & Yes & Yes & Yes & Yes \\
\hline Texas Observations Included? & No & No & No & No & Yes & Yes \\
\hline Number of Observations & 28645 & 28645 & 28645 & 28645 & 30493 & 30493 \\
\hline
\end{tabular}

Notes: The unit of observation is the employer-market-year. All specifications include change in demographic factor, change in lagged

market covariates, market and year fixed effects. HHI is scaled from 0 to 1.Standard errors are clustered by market. 
Table 6. The Impact of HHI on Premiums

Study Period: 1998-2002

\begin{tabular}{|c|c|c|c|c|}
\hline & \multirow{2}{*}{$\begin{array}{c}\text { Dep Var = Lagged HHI } \\
\text { First Stage Estimates }\end{array}$} & \multicolumn{3}{|c|}{ Dep Var = Annual Change in ln (Premium) } \\
\hline & & Reduced Form Estimates & IV Estimates & OLS Estimates \\
\hline $\operatorname{Sim} \Delta \mathrm{HHI} *($ Year $>=2001)$ & $\begin{array}{c}0.4751 * * * \\
(0.0136)\end{array}$ & $\begin{array}{c}0.1859 * * * \\
(0.0499)\end{array}$ & & \\
\hline Lagged HHI & & & $\begin{array}{c}0.3912 * * * \\
(0.1303)\end{array}$ & $\begin{array}{l}0.0151 \\
(0.0183)\end{array}$ \\
\hline \multicolumn{5}{|l|}{ Market-Year Controls } \\
\hline Lagged $\ln$ (Medicare costs per cap) & $\begin{array}{c}0.0336^{* *} \\
(0.0136)\end{array}$ & $\begin{array}{c}-0.0389 \\
(0.0355)\end{array}$ & $\begin{array}{l}-0.0521 \\
(0.0366)\end{array}$ & $\begin{array}{l}-0.0180 \\
(0.0344)\end{array}$ \\
\hline Lagged Unemp rate & $\begin{array}{c}0.2037 * * * \\
(0.0476)\end{array}$ & $\begin{array}{c}0.5672 * * * \\
(0.1550)\end{array}$ & $\begin{array}{c}0.4875^{* * *} \\
(0.1629)\end{array}$ & $\begin{array}{c}0.4741^{* * *} \\
(0.1616)\end{array}$ \\
\hline Lagged Hospital HHI & $\begin{array}{c}-0.0600 * * * \\
(0.0065)\end{array}$ & $\begin{array}{l}0.0025 \\
(0.0204)\end{array}$ & $\begin{array}{l}0.0260 \\
(0.0217)\end{array}$ & $\begin{array}{l}0.0055 \\
(0.0204)\end{array}$ \\
\hline \multicolumn{5}{|l|}{ Employer-market controls } \\
\hline$\Delta$ Demographic factor & $\begin{array}{c}0.0039 * * * \\
(0.0012)\end{array}$ & $\begin{array}{c}0.3226^{* * *} \\
(0.0055)\end{array}$ & $\begin{array}{c}0.3211^{* * *} \\
(0.0035)\end{array}$ & $\begin{array}{c}0.3226^{* * *} \\
(0.0034)\end{array}$ \\
\hline$\Delta$ Fraction of Self Insured Employees & $\begin{array}{l}0.0002 \\
(0.0012)\end{array}$ & $\begin{array}{c}0.0187 * * * \\
(0.0058)\end{array}$ & $\begin{array}{c}0.0186^{* * *} \\
(0.0039)\end{array}$ & $\begin{array}{c}0.0188^{* * * *} \\
(0.0038)\end{array}$ \\
\hline$\Delta$ Plan Design & $\begin{array}{c}0.0190^{*} \\
(0.0099)\end{array}$ & $\begin{array}{c}0.2234 * * * \\
(0.0402)\end{array}$ & $\begin{array}{c}0.2160 * * * \\
(0.0275)\end{array}$ & $\begin{array}{c}0.2221 * * * \\
(0.0272)\end{array}$ \\
\hline$\Delta$ Fraction in Indemnity Plans & $\begin{array}{l}0.0006 \\
(0.0021)\end{array}$ & $\begin{array}{c}0.0892 * * * \\
(0.0077)\end{array}$ & $\begin{array}{c}0.0890^{* * *} \\
(0.0054)\end{array}$ & $\begin{array}{c}0.0894 * * * \\
(0.0053)\end{array}$ \\
\hline$\Delta$ Fraction in HMO Plans & $\begin{array}{l}-0.0025 \\
(0.0017)\end{array}$ & $\begin{array}{c}-0.0806^{* * *} \\
(0.0089)\end{array}$ & $\begin{array}{c}-0.0796 * * * \\
(0.0056)\end{array}$ & $\begin{array}{c}-0.0805 * * * \\
(0.0056)\end{array}$ \\
\hline$\Delta$ Fraction in PPO Plans & $\begin{array}{l}0.0009 \\
(0.0015)\end{array}$ & $\begin{array}{l}0.0004 \\
(0.0062)\end{array}$ & $\begin{array}{l}0.0000 \\
(0.0047)\end{array}$ & $\begin{array}{l}0.0005 \\
(0.0047)\end{array}$ \\
\hline Number of Observations & 28645 & 28645 & 28645 & 28645 \\
\hline
\end{tabular}

Notes: The unit of observation is the employer-market-year. All specifications include employer, market and year fixed effects. HHI is scaled from 0 to 1.Standard errors are clustered by market. 
Table 7. The Impact of Consolidation on Plan Characteristics

Study Period: 1998-2002

Dependent Variable $=$ Annual Change in

\begin{tabular}{|c|c|c|c|c|c|c|}
\hline $\operatorname{Sim} \Delta H H I *$ post & $\begin{array}{c}-0.076 * * * \\
(0.016)\end{array}$ & $\begin{array}{c}-0.2819 * * * \\
(0.0976)\end{array}$ & $\begin{array}{c}-.1374 * \\
(0.0806)\end{array}$ & $\begin{array}{c}0.1803 * * * \\
(0.066)\end{array}$ & $\begin{array}{c}0.239 * * * \\
(0.0677)\end{array}$ & $\begin{array}{c}0.3259 * * * \\
(0.1455)\end{array}$ \\
\hline Texas Observations Included? & Yes & Yes & Yes & Yes & Yes & Yes \\
\hline Number of Observations & 30493 & 30493 & 30493 & 30493 & 30493 & 30493 \\
\hline
\end{tabular}

Notes: The unit of observation is the employer-market-year. All specifications include lagged market covariates, change in demographic factor, fraction of selfinsured patients, plan design, plantype shares and employer, market and year fixed effects. HHI is scaled from 0 to 1.Standard errors are clustered by market. 
Table 8. Descriptive Statistics (OES Survey Data)

\begin{tabular}{|c|c|c|c|c|}
\hline & 1999 & 2000 & 2001 & 2002 \\
\hline \multicolumn{5}{|l|}{ All Occupation Categories } \\
\hline Average Earnings & $\begin{array}{c}42251 \\
21262\end{array}$ & $\begin{array}{c}43957 \\
21782\end{array}$ & $\begin{array}{c}45446 \\
22030\end{array}$ & $\begin{array}{c}49134 \\
29010\end{array}$ \\
\hline No of Employees in Occupation-Market & $\begin{array}{c}1539 \\
5805\end{array}$ & $\begin{array}{c}1241 \\
4910\end{array}$ & $\begin{array}{l}1220 \\
4809\end{array}$ & $\begin{array}{c}1194 \\
4680\end{array}$ \\
\hline \multicolumn{5}{|l|}{ Physicians } \\
\hline Average Earnings & $\begin{array}{c}113494 \\
16655\end{array}$ & $\begin{array}{c}113301 \\
13630\end{array}$ & $\begin{array}{c}116318 \\
13257\end{array}$ & $\begin{array}{c}149584 \\
23923\end{array}$ \\
\hline No of Employees in Occupation-Market & $\begin{array}{l}1154 \\
2057\end{array}$ & $\begin{array}{l}1432 \\
2205\end{array}$ & $\begin{array}{c}1414 \\
2254\end{array}$ & $\begin{array}{c}1413 \\
1949\end{array}$ \\
\hline \multicolumn{5}{|l|}{ Nurses } \\
\hline Average Earnings & $\begin{array}{c}39601 \\
5292\end{array}$ & $\begin{array}{c}41245 \\
5908\end{array}$ & $\begin{array}{c}42982 \\
5896\end{array}$ & $\begin{array}{c}44211 \\
6186\end{array}$ \\
\hline No of Employees in Occupation-Market & $\begin{array}{c}16242 \\
18781\end{array}$ & $\begin{array}{c}16114 \\
17813\end{array}$ & $\begin{array}{c}16331 \\
17635\end{array}$ & $\begin{array}{c}16405 \\
17248\end{array}$ \\
\hline \multicolumn{5}{|l|}{ Totals } \\
\hline Number of Employees & 3398560 & 3657910 & 3758310 & 3771600 \\
\hline Number of Physicians & 106210 & 173260 & 173970 & 172370 \\
\hline Number of Nurses & 2030230 & 2030330 & 2057690 & 2050660 \\
\hline Number of Occupation Categories & 35 & 35 & 35 & 35 \\
\hline Number of Markets & 126 & 126 & 126 & 126 \\
\hline Number of Observations & 2209 & 2948 & 3081 & 3159 \\
\hline
\end{tabular}

Notes: The unit of observation is an occupation-market combination. Sample does not include markets present in the state of Texas, where the DoJ imposed restrictions on the Aetna-Prudential merger. The OES survey collects hourly wage data in 12 intervals. The mean wage value for each interval is calculated as the midpoint of the interval, except for the upper open-ended wage interval where the mean is set at the lower end of the range. From 2002 onward, the BLS estimates the mean wage for the upper open-ended interval using data collected from the National Compensation Survey. Standard deviations are in Italics. 
Table 9. Effect of the Aetna-Prudential Merger on Healthcare Provider Earnings and Employment

\begin{tabular}{|c|c|c|c|c|c|c|}
\hline \multirow[b]{2}{*}{ Simulated $\Delta \mathrm{HHI}$} & \multicolumn{3}{|c|}{$\begin{array}{c}\text { Dependent Variable }=\Delta \log _{99-02}(\text { Average Income }) \text { from } \\
\text { from }\end{array}$} & \multicolumn{3}{|c|}{ 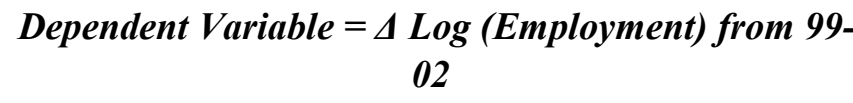 } \\
\hline & $\begin{array}{l}0.111 \\
(0.180)\end{array}$ & $\begin{array}{l}0.078 \\
(0.215)\end{array}$ & $\begin{array}{l}0.091 \\
(0.204)\end{array}$ & $\begin{array}{c}-2.372 * * \\
(0.809)\end{array}$ & $\begin{array}{c}-2.723 * * \\
(0.941)\end{array}$ & $\begin{array}{c}-2.437^{*} \\
(0.978)\end{array}$ \\
\hline Physician Indicator & $\begin{array}{c}0.193 * * * \\
(0.034)\end{array}$ & $\begin{array}{l}0.184 * * * \\
(0.035)\end{array}$ & N/A & $\begin{array}{c}0.523 * * \\
(0.170)\end{array}$ & $\begin{array}{c}0.497 * * \\
(0.167)\end{array}$ & N/A \\
\hline Physician $*$ Simulated $\Delta \mathrm{HHI}$ & $\begin{array}{c}-2.007^{*} \\
(0.833)\end{array}$ & $\begin{array}{c}-2.180 * * \\
(0.801)\end{array}$ & $\begin{array}{c}-2.195 * * \\
(0.811)\end{array}$ & $\begin{array}{l}-2.507 \\
(7.934)\end{array}$ & $\begin{array}{l}-2.582 \\
(8.441)\end{array}$ & $\begin{array}{c}-2.858 \\
(8.439)\end{array}$ \\
\hline Nurse Indicator & $\begin{array}{c}-0.013^{*} \\
(0.006)\end{array}$ & $\begin{array}{c}-0.015 * * \\
(0.006)\end{array}$ & N/A & $\begin{array}{l}-0.154 * * * \\
\quad(0.025)\end{array}$ & $\begin{array}{l}-0.160 * * * \\
\quad(0.027)\end{array}$ & N/A \\
\hline Nurse * Simulated $\Delta \mathrm{HHI}$ & $\begin{array}{c}0.440^{*} \\
(0.221)\end{array}$ & $\begin{array}{c}0.471+ \\
(0.257)\end{array}$ & $\begin{array}{c}0.457+ \\
(0.254)\end{array}$ & $\begin{array}{l}1.707^{*} \\
(0.845)\end{array}$ & $\begin{array}{c}2.012+ \\
(1.071)\end{array}$ & $\begin{array}{c}1.738+ \\
(1.032)\end{array}$ \\
\hline$\Delta$ Hospital HHI, 1999-2002 & $\begin{array}{l}0.023 \\
(0.029)\end{array}$ & $\begin{array}{l}0.021 \\
(0.031)\end{array}$ & $\begin{array}{l}0.024 \\
(0.032)\end{array}$ & $\begin{array}{c}-0.024 \\
(0.254)\end{array}$ & $\begin{array}{l}-0.027 \\
(0.247)\end{array}$ & $\begin{array}{l}-0.067 \\
(0.235)\end{array}$ \\
\hline Trend in Dep Var, 1997-1998 & No & Yes & Yes & No & Yes & Yes \\
\hline Occupation Fixed Effects & No & No & Yes & No & No & Yes \\
\hline \# Observations & 2110 & 1631 & 1631 & 2110 & 1631 & 1631 \\
\hline
\end{tabular}

Notes: Unit of observation is the occupation-market-year. All physician occupations are lumped into one category. Specifications are restricted to ocupation- markets present in both 1999 and 2002. Simulated HHI is scaled from 0 to 1. Sample does not include observations from Texas. All specifications are weighted by average estimated employment in each occupation-market. Standard errors are clustered by market.

*** signifies $p<.01$, ** signifies $p<.05$, * signifies $p<.10$ 


\section{Appendix: Representativeness of the LEHID Dataset}

This appendix compares the LEHID data to the two leading alternative sources of insurance data: the Kaiser Family Foundation/Health Retirement Education Trust (KFF/HRET) Annual Survey of Employer Benefits, and the proprietary Interstudy database of insurer data. The KFF/HRET survey randomly samples public and private employers to obtain national statistics on employersponsored health insurance; approximately 2000 employers respond each year. The data are not publicly available, nor is the sample designed to provide estimates at the market level. However, the survey is designed to yield representative estimates of national trends. Appendix Figure 1 below reports the annual growth rate in premiums for a family of four in an employer-sponsored plan. As in LEHID, both employer and employee premium contributions are combined, and both fully and self-insured plans are included. However, LEHID does not report premiums for a standard family size. Thus, to obtain a comparable measure from the LEHID sample, we divide the average annual premium in LEHID by the demographic factor. According to our source, this yields the premium per "person equivalent.” Annual growth rates for this “individual” premium are reported in Appendix Figure 1 as well. The trends are quite similar throughout the period.

We also compare our measures of market concentration with measures constructed by other researchers using the proprietary InterStudy database. InterStudy reports enrollment and premium figures at the insurer and MSA level. We compare the HHI and number of carriers tabulated by Scanlon et al (2008) to the corresponding figures from the LEHID data. ${ }^{40}$

Before describing the results, we note the InterStudy data is not directly comparable to LEHID for several reasons. The InterStudy data includes only fully-insured HMO plans for the time period we consider, and the allocation of enrollment across geographic markets is fairly noisy. In addition to these issues, the LEHID geographic markets, which generally correspond to MSAs (but may include multiple MSAs), are often larger than the Interstudy markets. ${ }^{41}$

\footnotetext{
${ }^{40}$ Our sincere thanks to Mike Chernew, Dennis Scanlon and Woolton Lee for sharing their estimates of market structure. For details on the construction of the InterStudy HHIs, see Scanlon et al (2006).

${ }^{41}$ For example, the entire state of Maine, is a single geographic market in the LEHID data.
} 
To compare measures of insurer market structure derived from the two sources, we begin by mapping MSAs to the corresponding LEHID markets. ${ }^{42}$ When multiple MSAs comprise one LEHID market, we weight the InterStudy MSA measures of market structure by the population of that MSA (obtained from the 2000 Census) to create measures of insurer market concentration (HHI, number of carriers) for each geographic market defined in the LEHID dataset.

When we use all plans in the LEHID dataset to construct HHI (as in our regression models), the correlation coefficient between the two measures is 0.18 over the entire sample period (1998-2006). This figure rises to 0.31 when we restrict attention to HMO plans only. ${ }^{43}$ As is apparent in Appendix Figure 2, there are also some differences between the two estimates when we compare trends over time. The LEHID HHI exhibits fairly steady growth in the latter half of the study period while the Interstudy HHI peaks in 2003. Unfortunately, there are no obvious explanations for these discrepancies.

We use the LEHID-based HHI estimates for theoretical and practical reasons. First, the set of carriers that serve large, multisite firms such as those included in LEHID may differ from the set of carriers at large. Thus, LEHID itself likely offers the best estimate of the relevant insurance market structure. Second, the InterStudy data does not consistently include PPO enrollment during our study period, and PPOs account for a large share of our data. Third, as noted above, researchers have documented serious concerns about the way in which InterStudy allocates enrollment across MSAs. Finally, the InterStudy data is quite expensive to acquire.

\footnotetext{
${ }^{42}$ We were able to find a match for 284 out of a total of 328 MSAs present in the Interstudy dataset

${ }^{43}$ Note that the InterStudy estimates include only fully-insured plans, while the LEHID estimates include both fullyinsured and self-insured plans. If we construct LEHID HHIs using only fully-insured plans, the corresponding correlation coefficients are .27 and .32 respectively.
} 


\section{Appendix Figure 1: Annual Premium Growth, LEHID vs. KFF/HRET}

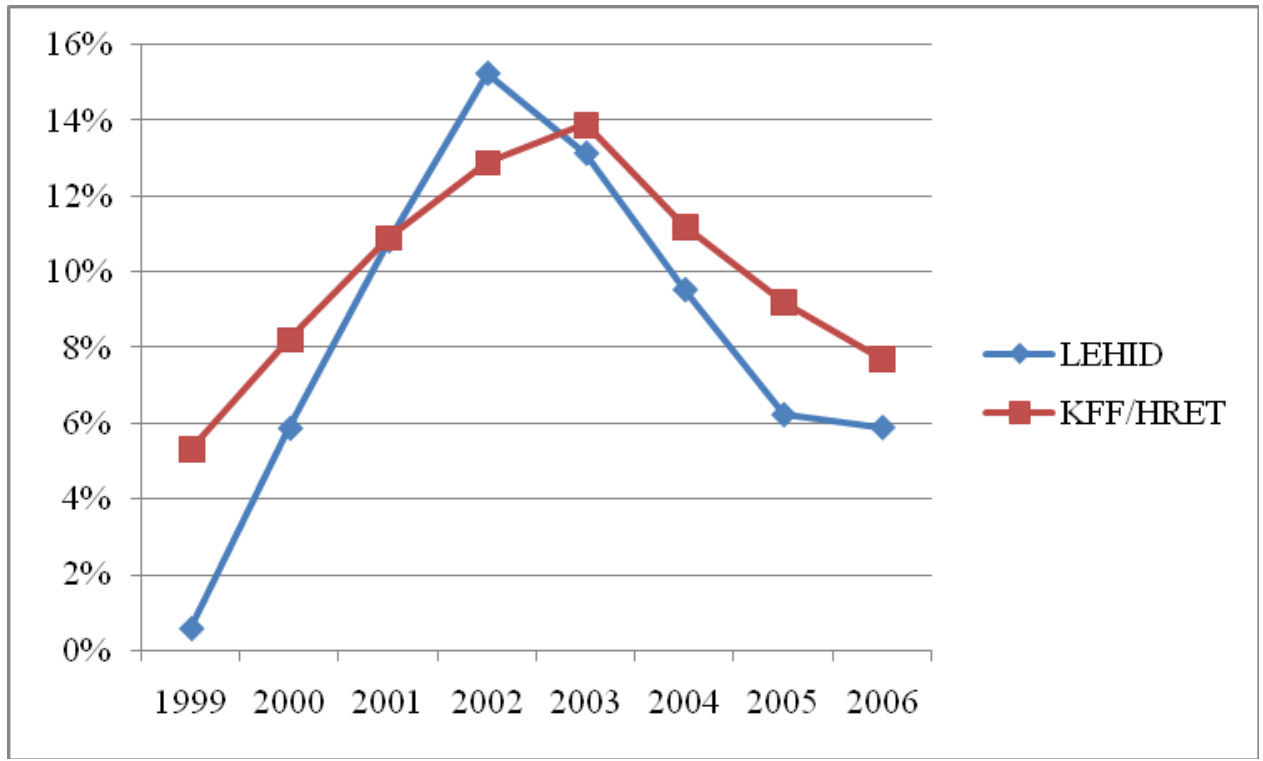

Sources: LEHID sample (all plans), and 2007 Kaiser/HRET Annual Survey of Employer-Sponsored Health Benefits Annual growth rates for the LEHID sample are calculated using employee-weighted average premiums/demographic factor for each year. Both sources combine fully insured and self-insured plans. 


\section{Appendix Figure 2. Comparison of Trends in LEHID vs. Interstudy HHI}

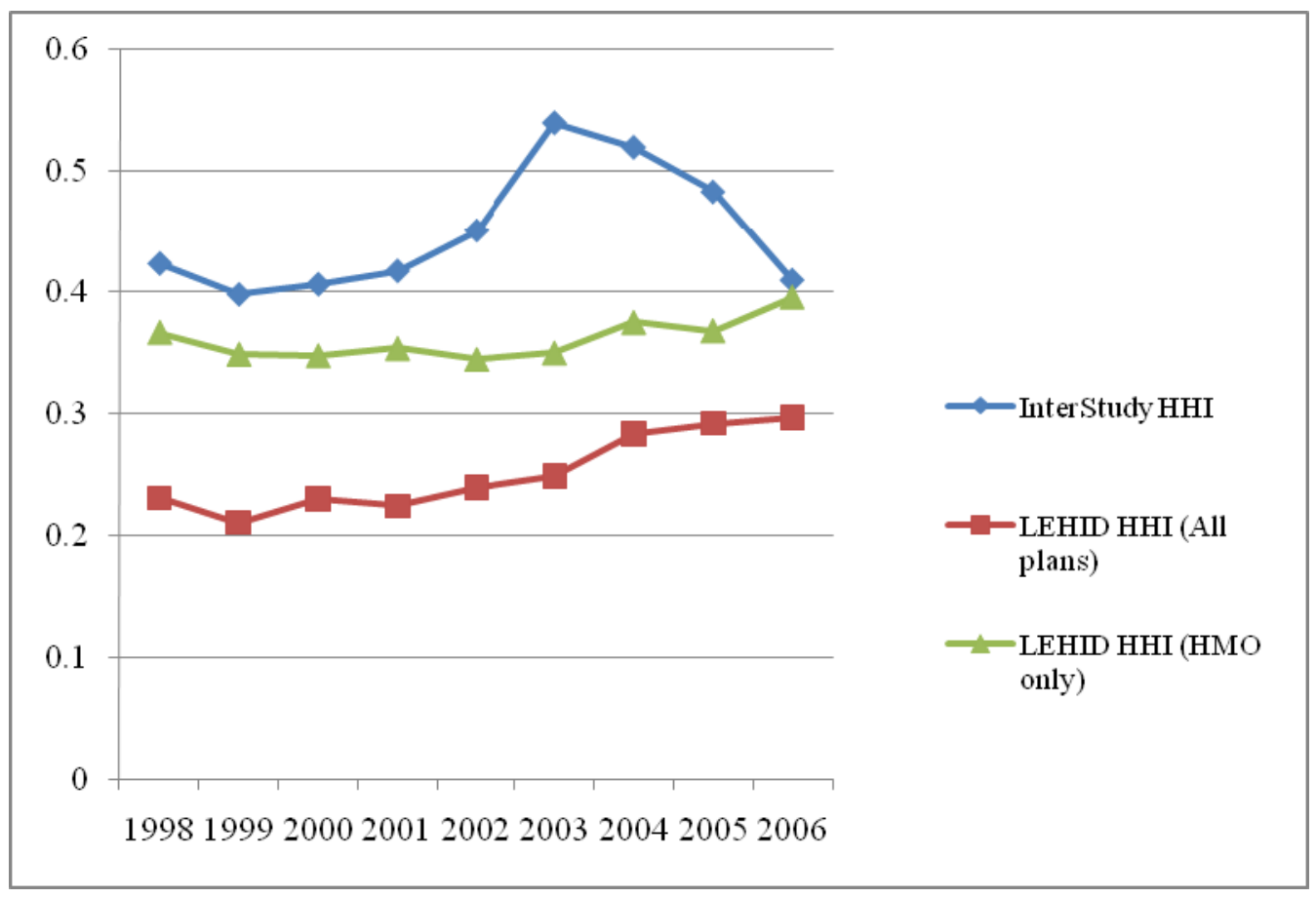

Sources: LEHID sample (all plans), InterStudy database 